\title{
A Combined Experimental and Tddft-dft Investigation of Structural and Optical Properties of Novel Pyrazole-1, 2, 3-triazole Hybrids as Optoelectronic Devices
}

\author{
Islam H. El Azab
}

Taif University

A. Ibrahim

Tanta University

M. Abdel El-Moneim

Port-Said University

M. Sh. Zoromba

Port-Said University

Mohamed Helmy Abdel-Aziz ( $\nabla$ helmy2002@gmail.com )

Alexandria University Faculty of Engineering https://orcid.org/0000-0002-3075-4968

\section{Bassyouni}

Port Said University
A. F. Al-Hossainy
New Valley University

\section{Research Article}

Keywords: [4ph-TAzole]TF, Thin film, DFT-TDDFT data, Optoelectronic properties

Posted Date: March 5th, 2021

DOl: https://doi.org/10.21203/rs.3.rs-260560/v1

License: (c) (1) This work is licensed under a Creative Commons Attribution 4.0 International License. Read Full License 


\section{A combined experimental and TDDFT-DFT investigation of structural and optical properties of Novel Pyrazole-1, 2, 3-Triazole hybrids as optoelectronic devices}

Islam H. El Azab ${ }^{1}$, A. Ibrahim², M. Abdel El-Moneim³ , M. Sh. Zoromba ${ }^{3,4}$, M. H. Abdel-Aziz ${ }^{4,5}$, M. Bassyouni ${ }^{6,7}$ A. F. Al-Hossainy ${ }^{8,9}$

\footnotetext{
${ }^{1}$ Chemistry Department, College of Science, Taif University, P.O. box 11099, Taif 21944, Saudi Arabia. ${ }^{2}$ Physics Department, Faculty of Science, Tanta University, Tanta 31527, Egypt.

${ }^{3}$ Chemistry Department, Faculty of Science, 23 December Street, 42521, Port-Said University, Port-Said, Egypt

${ }^{4}$ Chemical and Materials Engineering Department, King Abdulaziz University, Rabigh 21911, Saudi Arabia

${ }^{5}$ Chemical Engineering Department, Faculty of Engineering, Alexandria University, Alexandria 21544, Egypt

${ }^{6}$ Department of Chemical Engineering, Faculty of Engineering, Port Said University, Port Fouad 42511, Egypt

${ }^{7}$ Materials Science Program, University of Science and Technology, Zewail City of Science and Technology,

October Gardens, 6th of October, Giza 12578, Egypt

${ }^{8}$ Chemistry Department, Faculty of Science, New Valley University, 72511 Al-Wadi Al-Gadid, Al-Kharga, Egypt.

${ }^{9}$ Chemistry Department, Faculty of Science, Northern border University, Arar, Saudi Arabia.
}

\section{Abstract}

A conjugated semiconductor thin film of 1-((3-(3-(3,5-diphenyl-4,5-dihydro-1H-pyrazol-1-yl)-5-methyl1H-1,2,4-triazol-1-yl)-1-phenyl-1H-pyrazol-4-yl)methyl)-4-phenyl-1H-1,2,3-triazole $\quad$ [4ph-TAzole] ${ }^{\mathrm{TF}}$ was synthesized. The characterization of the obtained $[4 \mathrm{ph}-\mathrm{TAzole}]^{\mathrm{TF}}$ powder is carried out using different techniques includes FTIR, UV-Vis, ${ }^{1} \mathrm{HNMR}$, XRD, and mass spectra. The fabricated [4phTAzole $]^{\mathrm{TF}}$ thin film with a thickness of $150 \pm 3 \mathrm{~nm}$ is manufactured by physical vapor deposition technique (PVD) at a low deposition rate with basic pressure of the chamber was $5 \times 10^{-5} \mathrm{mbar}$. Using DFT-TDDFT simulation, the structure measurements can determine the energy gap and optical properties. The obtained DFT-TDDFT data provide good proof for the electronic transition in zerodimensional [4ph-TAzole] ${ }^{\mathrm{TF}}$ as a single crystal molecule. This study provides valuable information on the nature and sources of defect formation and electronic transition in conductor organic derivate of triazole which open the way for the application as an optoelectronic device. Application Davis's and Shilliday's equation on [4ph-TAzole] ${ }^{\mathrm{TF}}$ mentioned that the $\mathrm{E}_{\mathrm{g}}^{\mathrm{Dir}}$ and $\mathrm{E}_{\mathrm{g}}^{\mathrm{Ind}}$ transitions can be computed by plotting $(\alpha h v)^{2}$ and $(\alpha h v)^{0.5}$ versus hv nearby the value of fundamental band edge $\left((\alpha h v)^{2}\right.$ and $(\alpha h v)^{0.5}$ parts) in the computed Abs. $(\lambda)$ curves to zero absorption value, respectively. The direct and indirect energies were $2.651 \mathrm{eV}$ and $3.01 \mathrm{eV}$ for [4ph-TAzole] ${ }^{\mathrm{TF}}$, respectively. The obtained thin film presents a promising result to be a good candidate for organic derivate of triazole solar cell applications.

Keywords: [4ph-TAzole $]^{\mathrm{TF}}$; Thin film; DFT-TDDFT data; Optoelectronic properties,

*Corresponding author email: mhmossa@kau.edu.sa (M. H. Abdel-Aziz) ; mzoromba@kau.edu.sa (<. Sh. Zoromba); ahmed73chem@nvu.edu.eg (A. F. Al-Hossainy) 


\section{Introduction}

During the last two decades, several efforts have been oriented for converting the solar energy into electricity, using dye-sensitized solar cells (DSSCs) owing to their high conversion potency and their potential low cost [1]. To advance the act of DSSCs, a great effort of research is being achieved on semiconductor nanocrystalline titanium oxide $\left(\mathrm{TiO}_{2}\right)$ electrodes, [2] molecular dyes [3], electrolytes [4], and counter electrodes [5]. Organic moieties play a crucial role in photovoltaic and light collecting systems due to their admirable optical and electrical properties [6]. Recently organic fragments in practically, 1,2,3-triazoles have been used as additives in the electrolytic solution of DSSC [7,8]. Click reaction refers to $\mathrm{Cu}(\mathrm{I})$-catalyzed cycloaddition of azide to alkyne to furnish 1,2,3-triazole using slight reaction conditions in a good yield. 1,2,3-Triazole skeleton has an extensive range of applications in industrial, biological, and therapeutic fields [9,10]. Moreover, 1,2,3-triazole moiety acts as powerful Eacceptor component, usually utilized to modulate the HOMO or LUMO energy levels for low band gap features in optoelectronic and photo physical devices [11-14]. Based on the above-mentioned applications of 1,2,3-triazole unit, and to continue our efforts at annulation a new N-containing heterocycle [15-21], we report herein an efficient synthetic tactic for the preparation of 1,2,3-triazolebased frames, using azide-alkyne Huisgen cycloaddition reaction, to study its optical properties.

Herein, the following of triazole derivative, 1-((3-(3-(3,5-diphenyl-4,5-dihydro-1H-pyrazol-1-yl)-5methyl-1H-1,2,4-triazol-1-yl)-1-phenyl-1H-pyrazol-4-yl)methyl)-4-phenyl-1H-1,2,3-triazole $\quad$ as $\quad$ a photosensitizer agent was synthesized through $\mathrm{Cu}$-catalyzed azide-alkyne cycloaddition reactions. The direct and indirect energies were found to be $1.983 \mathrm{eV}$ and $2.121 \mathrm{eV}$ respectively for the thin film. The obtained thin film presents a promising result to be a good candidate for organic derivate of triazole solar cell applications.

\section{Materials and Methods}

\subsection{Raw Materials}

Chemicals were purchased from Sigma Aldrich (Bayouni Trading Co. Ltd., Al-Khobar, Saudi Arabia) and used without further purification. The reaction progress was checked out by TLC on silica gel precoated F254 Merck plates (Merck, Darmstadt, Germany). Spots were visualized by UV irradiation. 
Melting points were specified on a digital Gallen-Kamp MFB-595 instrument (Gallenkamp, London, UK) using open capillary tubes and were uncorrected. IR spectra were recorded as $\mathrm{KBr}$ discs using Bruker-Vector 22 FTIR spectrophotometer (Bruker, Manasquan, NJ, USA). The NMR spectra were recorded with a Varian Mercury VXR-300 NMR spectrometer (Bruker, Marietta, GA, USA) at 300 and $75 \mathrm{MHz}$ for ${ }^{1} \mathrm{H}$ and ${ }^{13} \mathrm{C}$ NMR spectra, respectively, using DMSO- $\mathrm{d}_{6}$ as the solvent. Mass spectra were recorded on a Hewlett Packard MS-5988 spectrometer (Hewlett Packard, Palo Alto, CA, USA) at 70 eV. Elemental analyses were conducted at the Micro-Analytical Center of Taif University, Taif, KSA.

\subsection{Synthetic procedures and analytic data of compounds}

3-(3,5-Diphenyl-4,5-dihydro-1H-pyrazol-1-yl)-5-methyl-1-(1-(2-phenylhydrazono)ethyl)-1H-1,2,4triazole (2). A mixture of the acetyl compound (1) [17] $(0.345 \mathrm{~g}, 1 \mathrm{mmol})$, phenylhydrazine $(0.108 \mathrm{~mL}$, $1 \mathrm{mmol})$ and crystalline sodium acetate $(0.34 \mathrm{~g}, 4.2 \mathrm{mmol})$ was refluxed in dry EtOH $(25 \mathrm{~mL})$ for $4 \mathrm{~h}$. After cooling, the reaction mixture was transferred onto $\mathrm{H}_{2} \mathrm{O}(100 \mathrm{~mL})$ and the isolated solid was filtered off, washed with $\mathrm{H}_{2} \mathrm{O}$, dried and recrystallized using EtOH to give compound 2 as yellow solid in a 75\% yield; mp 159-161 ${ }^{\circ} \mathrm{C}$; IR (KBr, $\left.v_{\max }, \mathrm{cm}^{-1}\right)$ : 1609-1623 (4C=N), $3190(\mathrm{~N}-\mathrm{H}) ;{ }^{1} \mathrm{H}$ NMR (300 MHz, DMSO-d $\left.)_{6}\right): \delta 1.05,2.45(\mathrm{~s}, 6 \mathrm{H}, 2 \mathrm{Me}), 3.52(\mathrm{dd}, \mathrm{J}=12.6$ and $4.8 \mathrm{~Hz}, 1 \mathrm{H}), 3.91(\mathrm{dd}, \mathrm{J}=8.8 \mathrm{and} 13.2 \mathrm{~Hz}$, 1H), $5.12(\mathrm{dd}, \mathrm{J}=10.1$ and $4.1 \mathrm{~Hz}, 1 \mathrm{H}), 6.86-7.89(\mathrm{~m}, 15 \mathrm{H}, \mathrm{Ar}-\mathrm{H}), 10.56\left(\mathrm{~s}, 1 \mathrm{H}, \mathrm{NH}_{\text {Deutr. Exch }}\right) ;{ }^{13} \mathrm{C} \mathrm{NMR}$ (75 MHz, DMSO-d $)$ ): 13.6, 14.9 (2 Me), $40.1\left(\mathrm{CH}_{2}\right), 60.2(\mathrm{CH}), 113.8,122.3,126.8,126.8,128.2,128.6$, 128.9, 129.6, 131.0, 136.4, 143.1, 143.5 (C-Ar), 145.6, 151.6, 152.1, $157.2(4 \mathrm{C}=\mathrm{N}-)$; MS (m/z, \%): 435.22 ( $\mathrm{M}^{+}$, 10). Anal. Calcd for $\mathrm{C}_{26} \mathrm{H}_{25} \mathrm{~N}_{7}$ (435.52): $\mathrm{C}, 71.70 ; \mathrm{H}, 5.79 ; \mathrm{N}, 22.51 \%$. Found: $\mathrm{C}, 71.42 ; \mathrm{H}$, $5.54 ; \mathrm{N}, 22.22 \%$.

\section{3-(3-(3,5-Diphenyl-4,5-dihydro-1H-pyrazol-1-yl)-5-methyl-1H-1,2,4-triazol-1-yl)-1-phenyl-1H-} pyrazole-4-carbaldehyde (3)

It was prepared under Vilsmeier-Haack reagent; $\mathrm{POCl}_{3}(1.17 \mathrm{~mL}, 10 \mathrm{~mol})$ was added dropwise to DMF $(15 \mathrm{~mL})$ at $0^{\circ} \mathrm{C}$. After $30 \mathrm{~min}$, a solution of the hydrazone $2(0.435 \mathrm{~g}, 1 \mathrm{mmol})$ in $\mathrm{DMF}(10 \mathrm{~mL})$ was added dropwise at $0^{\circ} \mathrm{C}$ under stirring. The reaction mixture was stirred at $0^{\circ} \mathrm{C}$ for $2 \mathrm{~h}$ and at $70^{\circ} \mathrm{C}$ for further $1 \mathrm{~h}$. Afterwards the reaction mixture was cooled to ambient temperature and transferred onto 
mashed ice. The separated product was collected, washed with $\mathrm{H}_{2} \mathrm{O}$, dried and recrystallized using EtOH to furnish the formyl compound $\mathbf{3}$ as yellow crystals in a $70 \%$ yield; mp $173-175^{\circ} \mathrm{C}$; IR $\left(\mathrm{KBr}, v_{\max }, \mathrm{cm}^{-}\right.$ $\left.{ }^{1}\right): 1522(\mathrm{C}=\mathrm{C}), 1609-1623(4 \mathrm{C}=\mathrm{N}), 1720(\mathrm{C}=\mathrm{O}), 2858\left(\mathrm{CH}_{3} / \mathrm{CH}_{2 \mathrm{sym}}\right), 2923\left(\mathrm{CH}_{3} / \mathrm{CH}_{2}\right.$ asym $) ;{ }^{1} \mathrm{H}$ NMR (300 MHz, DMSO-d $): \delta 2.51(\mathrm{~s}, 3 \mathrm{H}, \mathrm{Me}), 3.52(\mathrm{dd}, \mathrm{J}=12.6$ and $4.8 \mathrm{~Hz}, 1 \mathrm{H}), 3.91(\mathrm{dd}, \mathrm{J}=8.8$ and 13.2 $\mathrm{Hz}, 1 \mathrm{H}), 5.12(\mathrm{dd}, \mathrm{J}=10.1$ and $4.1 \mathrm{~Hz}, 1 \mathrm{H}), 6.86-7.89(\mathrm{~m}, 15 \mathrm{H}, \mathrm{Ar}-\mathrm{H}), 8.41(\mathrm{~s}, 1 \mathrm{H}$, pyrazole $(\mathrm{C} 5)-\mathrm{H})$, 10.01 (s, 1H, CHO); ${ }^{13} \mathrm{C}$ NMR (75 MHz, DMSO-d 6 ): $13.6(\mathrm{Me}), 40.1\left(\mathrm{CH}_{2}\right), 60.2(\mathrm{CH}), 114.0,119.8$, 126.2, 126.7, 126.9, 128.2, 128.6, 128.9, 129.2, 129.3, 131.0, 136.4, 139.7, 143.5 (C-Ar), 151.6, 152.1, 157.2, $164.0(4 \mathrm{C}=\mathrm{N}-)$; MS (m/z, \%): $473.20\left(\mathrm{M}^{+}, 30\right)$. Anal. Calcd for $\mathrm{C}_{28} \mathrm{H}_{23} \mathrm{~N}_{7} \mathrm{O}$ (473.53): C, 71.02; H, 4.90; N, 20.71\%. Found: C, 69.87; H, 4.62; N, 20.49\%.

\section{(3-(3-(3,5-Diphenyl-4,5-dihydro-1H-pyrazol-1-yl)-5-methyl-1H-1,2,4-triazol-1-yl)-1-phenyl-1H-}

pyrazol-4-yl)methanol (4). To the solution of the formyl compound $3(0.473 \mathrm{~g}, 1 \mathrm{mmol})$ in dry $\mathrm{MeOH}$ $(25 \mathrm{~mL})$, a solution of $\mathrm{NaBH}_{4}(0.1 \mathrm{~g})$ in dry $\mathrm{MeOH}(10 \mathrm{~mL})$ was added dropwise and reaction mixture was stirred at RT for $1 \mathrm{~h}$. (TLC monitored). Afterwards, the solvent was evaporated under vacuum, the residue was triturated with ethyl acetate yielded the primary alcohol analogy $\mathbf{4}$ as brownish-yellow solid in an $85 \%$ yield; mp $198-200{ }^{\circ} \mathrm{C}$; IR $\left(\mathrm{KBr}, v_{\max }, \mathrm{cm}^{-1}\right): 1522(\mathrm{C}=\mathrm{C}), 1609-1623(4 \mathrm{C}=\mathrm{N}), 2858$ $\left(\mathrm{CH}_{3} / \mathrm{CH}_{2 \mathrm{sym}}\right), 2923\left(\mathrm{CH}_{3} / \mathrm{CH}_{2}\right.$ asym $), 3215(\mathrm{OH}) ;{ }^{1} \mathrm{H}$ NMR (300 MHz, DMSO-d $)$ ): $\delta 2.51$ (s, 3H, Me), $3.52(\mathrm{dd}, \mathrm{J}=12.6$ and $4.8 \mathrm{~Hz}, 1 \mathrm{H}), 3.65\left(\mathrm{~s}, 1 \mathrm{H}, \mathrm{OH}_{\text {Deutr. Exch }}\right), 3.91(\mathrm{dd}, \mathrm{J}=8.8$ and $13.2 \mathrm{~Hz}, 1 \mathrm{H}), 4.60$ (s, $\left.2 \mathrm{H}, \mathrm{CH}_{2}\right), 5.12(\mathrm{dd}, \mathrm{J}=10.1$ and $4.1 \mathrm{~Hz}, 1 \mathrm{H}), 6.86-7.89(\mathrm{~m}, 15 \mathrm{H}, \mathrm{Ar}-\mathrm{H}), 8.29(\mathrm{~s}, 1 \mathrm{H}$, pyrazole $(\mathrm{C} 5)-\mathrm{H})$; MS (m/z, \%): $475.21\left(\mathrm{M}^{+}, 5\right)$. Anal. Calcd for $\mathrm{C}_{28} \mathrm{H}_{25} \mathrm{~N}_{7} \mathrm{O}$ (475.54): C, 70.72; H, 5.30; N, 20.62\%. Found: C, $70.48 ; H, 5.12 ; \mathrm{N}, 20.36 \%$.

\section{1-(4-(Azidomethyl)-1-phenyl-1H-pyrazol-3-yl)-3-(3,5-diphenyl-4,5-dihydro-1H-pyrazol-1-yl)-5-}

methyl-1H-1,2,4-triazole (6). To an ice-cold solution of the hydroxy methyl compound 4 (0.475 g, 1 $\mathrm{mmol})$ and $\mathrm{Et}_{3} \mathrm{~N}(0.3 \mathrm{~mL})$ in dry $\mathrm{DCM}(20 \mathrm{~mL}), \mathrm{MeSO}_{2} \mathrm{Cl}(6 \mathrm{mmol})$ in $\mathrm{DCM}(10 \mathrm{~mL})$ was added dropwise through $30 \mathrm{~min}$, afterwards the mixture was stirred at RT for further $2 \mathrm{~h}$ (TLC). The solvent was removed; the crude mass was triturated thrice using DCM $(20 \mathrm{~mL})$. The organic layer was washed with brine and dried over anhydrous $\mathrm{Na}_{2} \mathrm{SO}_{4}$ that furnished methanesulfonate intermediate $\mathbf{5}$. Then, to a solution of methanesulfonate analogy $(0.553 \mathrm{~g}, 1 \mathrm{mmol})$ in DMSO $(20 \mathrm{~mL}), \mathrm{NaN}_{3}(6 \mathrm{mmol})$ was added 
and the reaction mixture was stirred at $60^{\circ} \mathrm{C}$ for $4 \mathrm{~h}$. (checked by TLC). Then, reaction mixture was transferred onto $\mathrm{H}_{2} \mathrm{O}(100 \mathrm{~mL})$ and extracted thrice with ethyl acetate $(25 \mathrm{~mL})$. The organic layer was dried over anhydrous $\mathrm{Na}_{2} \mathrm{SO}_{4}$, and the residual was recrystallized using flash chromatography to yield the azidomethyl compound 6 as off-white solid in an $82 \%$ yield; mp $218-220{ }^{\circ} \mathrm{C}$; IR $\left(\mathrm{KBr}, v_{\max }, \mathrm{cm}^{-1}\right)$ : $2101\left(\mathrm{~N}_{3}\right), 1522(\mathrm{C}=\mathrm{C}), 1609-1623(4 \mathrm{C}=\mathrm{N}), 2858\left(\mathrm{CH}_{3} / \mathrm{CH}_{2 \mathrm{sym}}\right), 2923\left(\mathrm{CH}_{3} / \mathrm{CH}_{2}\right.$ asym $) ;{ }^{1} \mathrm{H}$ NMR $(300$ MHz, DMSO-d $\left.)_{6}\right): 2.51\left(\mathrm{~s}, 2 \mathrm{H}, \mathrm{CH}_{2}\right), 2.68(\mathrm{~s}, 3 \mathrm{H}, \mathrm{Me}), 3.52(\mathrm{dd}, \mathrm{J}=12.6$ and $4.8 \mathrm{~Hz}, 1 \mathrm{H}), 3.91$ (dd, J $=8.8$ and $13.2 \mathrm{~Hz}, 1 \mathrm{H}), 5.12(\mathrm{dd}, \mathrm{J}=10.1$ and $4.1 \mathrm{~Hz}, 1 \mathrm{H}), 6.86-7.89(\mathrm{~m}, 15 \mathrm{H}, \mathrm{Ar}-\mathrm{H}), 8.29(\mathrm{~s}, 1 \mathrm{H}$, pyrazole $(\mathrm{C} 5)-\mathrm{H}) ; \mathrm{MS}(\mathrm{m} / \mathrm{z}, \%): 500.21\left(\mathrm{M}^{+}, 35\right)$. Anal. Calcd for $\mathrm{C}_{28} \mathrm{H}_{24} \mathrm{~N}_{10}(500.56): \mathrm{C}, 67.19 ; \mathrm{H}, 4.83$; N, 27.98\%. Found: C, 67.02; H, 4.58; N, 27.65\%.

1-((3-(3-(3,5-Diphenyl-4,5-dihydro-1H-pyrazol-1-yl)-5-methyl-1H-1,2,4-triazol-1-yl)-1-phenyl-1Hpyrazol-4-yl)methyl)-4-phenyl-1H-1,2,3-triazole (7) $[4 \mathrm{ph}-\mathrm{TAzole}]^{\mathrm{TF}}$. A mixture of the azidomethyl compound 6 (0.50 g, $1 \mathrm{mmol})$, phenylacetylene $(0.10 \mathrm{~mL}, 1 \mathrm{mmol})$, Na-ascorbate $(1 \mathrm{mmol})$ and $\mathrm{CuSO}_{4} .5 \mathrm{H}_{2} \mathrm{O}(0.25 \mathrm{mmol})$ in $\mathrm{DMF}-\mathrm{H}_{2} \mathrm{O}(5: 1,7 \mathrm{~mL})$ was stirred at $75^{\circ} \mathrm{C}$ for $9 \mathrm{~h}$ (TLC monitored). Next, reaction mixture was transferred to $\mathrm{H}_{2} \mathrm{O}$ and extracted thrice with ethyl acetate $(30 \mathrm{~mL})$. The obtained matter was purified by flash chromatography (toluene: ethyl acetate $(7: 3))$, to provide the target [4phTAzole $]^{\mathrm{TF}}(7)$, as amorphous brown powder in a $71 \%$ yield; $\mathrm{mp} 238-240{ }^{\circ} \mathrm{C}$.

\subsection{Fabrication thin film}

The triazole derivates $[4 \mathrm{ph}-\mathrm{TAzole}]^{\mathrm{TF}}$ thin films were fabricated to investigate the conductivity of the thin film [22]. Thin films were prepared with Physical Vapor Disposal (PVD). The fabricated thin films have been deposited onto ITO/glass substrate and/or single crystal of wafer at an initial pressure of $5 \times 10^{-5}$ mbar, inter-digitized electrodes separated by $75 \mu \mathrm{m}$. The application of UNIVEX 250 Leybold (Germany), two Tantalum boats at any point without vacuum breaking, and the deposition rate $3 \AA$ 解 [23]. A quartz crystalline micro-balance with UNIVEX 250 Leybold is shown in Fig.1a for prepared the films' thickness with approx. $200 \mathrm{~nm}$. The different steps to prepare [4ph-TAzole ${ }^{\mathrm{TF}}$ thin films is represented by Fig. 1b. 
(a)
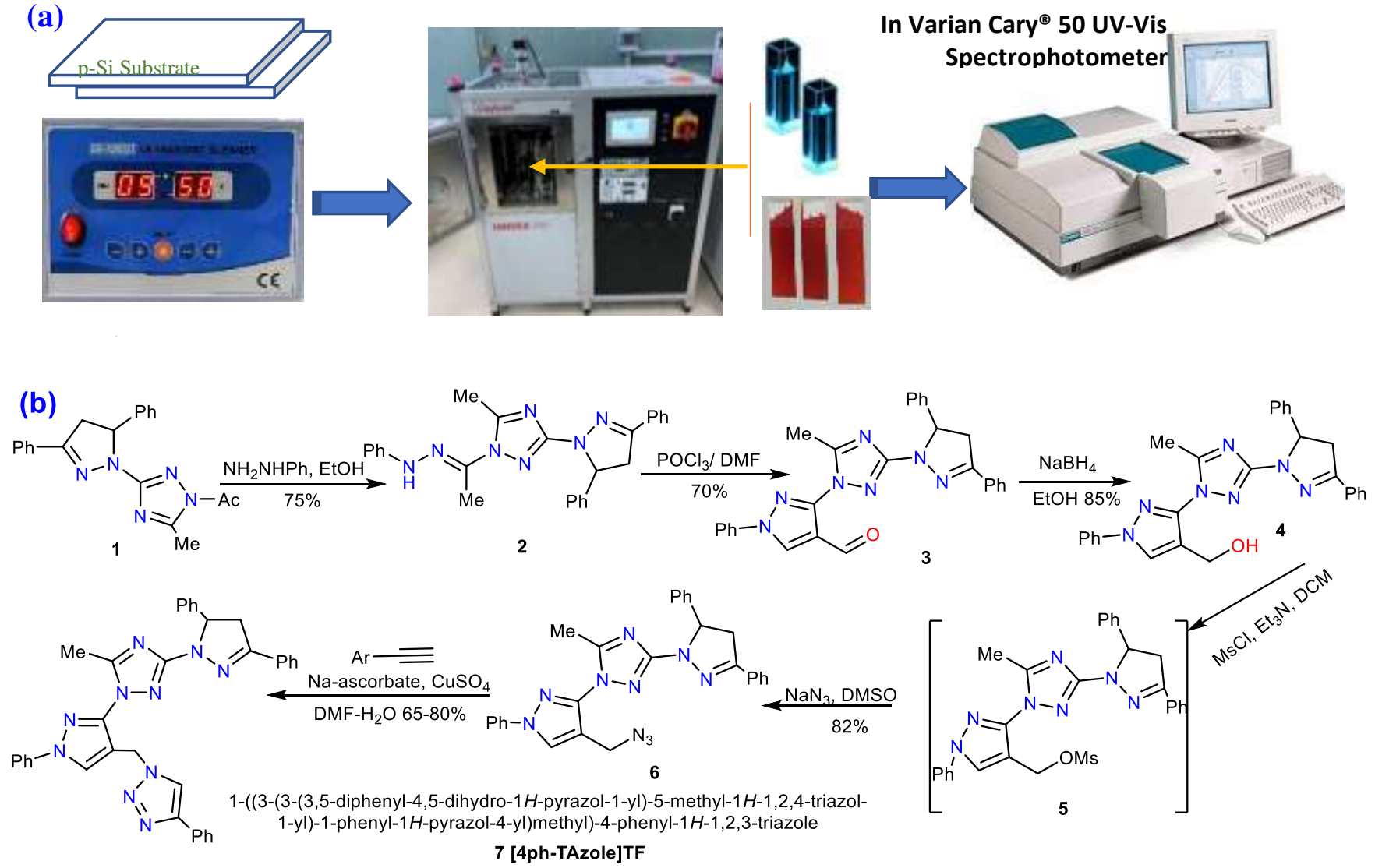

Fig. 1 (a-b) Fabrication and chemical structure of [4ph-TAzole $]^{\mathrm{TF}}$ thin film.

\subsection{Computational study}

The result from CATSTEP and $\mathrm{DMol}^{3}$ calculations was used to test the efficiency of the molecular structure and frequency measurements for [4ph-TAzole $]^{\mathrm{TF}}$ in the gas phase according to the DFTTDDFT study. Estimated evidence from functional correlation exchange of PBE and GGA, normal pseudo-potential conservative, and the basis set of DNPs were measured using DMol ${ }^{3}$ and CATSTEP programmed for tolerable molecules, correspondingly [24]. In computer computations, the extent of the plane-wave cut-off power utilized was $830 \mathrm{eV}$. Physical and spectroscopic [4ph-TAzole] ${ }^{\mathrm{TF}}$ features for instance the XRD and optical features have been established from DMol ${ }^{3}$, and CATSTEP resulted in GP frequency approximation. Along with the non-locally needy three factors altercation relationship functional of the Becker [25] with the Lee-Yang Parr relationship purposeful (B3LYP/WBX97XD/6-311G) [26], improved shape and vibrating regularity (IR) extents on doped [4ph-TAzole $]^{\mathrm{TF}}$ in the gas phase were carried out. The GAUSSIAN 09W programmed framework tests the symmetrical factors, the images of improved arrangements, vibration manners, and energy of nanocomposite mixtures manufactured. DFT scheming with the B3LYP technique grounded on 
WBX97XD/6-311 G has provided numerous worthy outcomes for the configuration-spectrum relationship in the studies published by our group [27], contains some important results from experimental data. The GAP method was applied to estimate the Gaussian and CATSTEP doped $[4 \mathrm{ph}-\mathrm{TAzole}]^{\mathrm{TF}}$ representations in the gas phase, deliberate diversity of descriptors, the prototypical on overall vitalities and products, and the combined use of several variants with varying complexities [28].

\section{Results and Discussion}

\subsection{FT-IR spectroscopy}
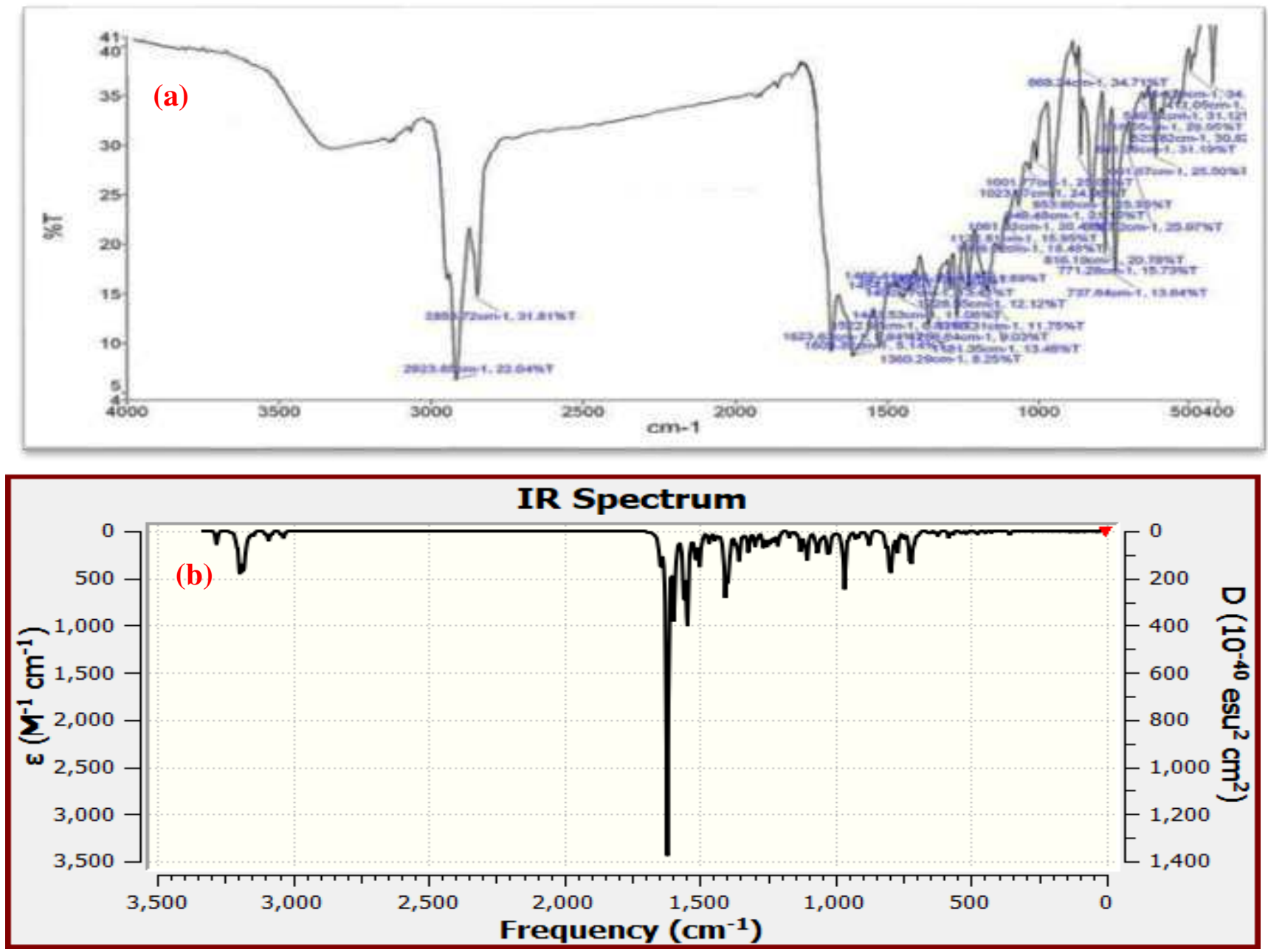

Fig. 1(a-b) Comparison of experimental and theoretical IR spectra of [4ph-TAzole] ${ }^{\mathrm{TF}}$ and [4ph-TAzole] isolated molecule in gaseous state, respectively.

Fig. 1a, revealed the FT-IR spectra that acquired at ambient temperature, confirmed the structure of the triazole derivate $[4 \mathrm{ph}-\mathrm{TAzole}]^{\mathrm{TF}}$. The (IR) spectrum, showed the absence of azide stretching signal initially detected in its parent azido analogy $\mathbf{6}(\mathrm{IR})$ at $2101 \mathrm{~cm}^{-1}$, instead a new stretching signal was observed at $1042 \mathrm{~cm}^{-1}$ for $\mathrm{C}-\mathrm{O}-\mathrm{C}$ moiety. A medium absorption signal located at $\approx 1522 \mathrm{~cm}^{-1}$, due to 
the two olefinic carbons, besides, a broad stretching band addressed around $\approx 1609-1623 \mathrm{~cm}^{-1}$ was assigned for the $\mathrm{C}=\mathrm{N}_{\text {str. }}$. The attendance of the $\mathrm{CH}_{3}$ and $\mathrm{CH}_{2}$ groups was confirmed through their starching bands at $2858\left(\mathrm{CH}_{3} / \mathrm{CH}_{2 \text { sym }}\right)$, and $2923\left(\mathrm{CH}_{3} / \mathrm{CH}_{2}\right.$ asym $)[29,30]$. The theoretical IR spectrum was approximated to require the spectroscopic signs of the [4ph-TAzole] isolated molecule in gaseous state. The small variations between the expected and evaluated frequencies are shown in Fig. 1b. The essential objective behind the distinction is that the count was carried out in a vacuum while the calculations were calibrated in a solid state. As the vibrational modes of the ligands studied are complex, they contribute to low symmetry and it is difficult to attribute the torsion as well as all plane modes because the ring modes degrade in addition to imitative ones. However, some apparent movements can be seen in the graph achieved $[31,32]$. The direct correlation among the calculated $\left(\lambda_{\text {Cal. }}\right)$ and experimental

wavenumbers $\left(\lambda_{\text {Exp. }}\right)$ is illustrated by the next equation for [4ph-TAzole] $: \lambda_{\text {Cal. }}=0.908 \lambda_{\text {Exp. }}+32.07$ with correlation coefficient $\left(\mathrm{R}^{2}=0.89\right)$.

\section{2. ${ }^{1} \mathrm{HNMR}$ and ${ }^{13} \mathrm{CNMR}$ spectroscopy}

Fig. 2 (a, b), offered the NMR- $\left({ }^{1} \mathrm{H},{ }^{13} \mathrm{C}\right)$ spectra of the now prepared 1,2,3-triazole dye [4ph-TAzole], respectively. The ${ }^{1} \mathrm{H}$ NMR spectrum of [4ph-TAzole], disclosed three singlet signals at $\delta 2.51,5.46$, and $8.29 \mathrm{ppm}$, confirmed the existence of $\mathrm{Me}, \mathrm{CH}_{2}-\mathrm{N}$, and pyrazole $(\mathrm{C} 5)-\mathrm{H}$, protons, respectively. Moreover, noteworthy proton resonances were noted at $3.52(\mathrm{dd}, \mathrm{J}=12.6,4.8 \mathrm{~Hz}, 1 \mathrm{H}$, pyrazole $(\mathrm{C} 4)-\mathrm{H}), 3.91(\mathrm{dd}, \mathrm{J}$ $\left.=8.8,13.2 \mathrm{~Hz}, 1 \mathrm{H}, \operatorname{pyrazole}_{(\mathrm{C} 4)}-\mathrm{H}\right)$, and $5.12(\mathrm{dd}, \mathrm{J}=10.1,4.1 \mathrm{~Hz}, 1 \mathrm{H}$, pyrazole $(\mathrm{C5})-\mathrm{H})$. The aromatic-Hs overlapped with triazole $_{(\mathrm{C} 4)}-\mathrm{H}(20 \mathrm{H})$, were presented as a multiplet signals centered around $\approx 6.86-7.89$ ppm. While ${ }^{13} \mathrm{C}$ NMR (75 MHz, DMSO- $\mathrm{d}_{6}$ ), of the [4ph-TAzole] day (7), displayed C-resonances at 13.6 (Me), 40.1, 43,8 (2 $\left.\mathrm{CH}_{2}\right), 60.2(\mathrm{CH}), 117.0,117.2,117.4,118.3,119.4,121.1,125.7,126.6,126.7,126.8$, $128.5,128.6,128.6,130.0,131.8,136.8,142.5,143.7$ (C-Ar), 151.7, 154.1, 156.8, 164.6 (4 C=N-).

The theoretical ${ }^{1} \mathrm{HNMR}$ spectrum was approximated to require the spectroscopic signs of the [4phTAzole] isolated molecule in gaseous state. The small variations between the expected and evaluated number of protons and chemical shift are shown in Fig. 1b. The essential objective behind the distinction is that the count was carried out in a vacuum while the calculations were calibrated in a solid state. As the 
Nuclear Magnetic Resonance (NMR) spectroscopy of [4ph-TAzole] studied are complex, they contribute to low symmetry and it is difficult to attribute the torsion as well as all plane modes because the ring modes degrade in addition to imitative ones. However, some apparent movements can be seen in the graph achieved $[33,34]$. The direct correlation among the calculated $\left(\lambda_{\text {Cal. }}\right)$ and experimental wavenumbers $\left(\lambda_{\text {Exp. }}\right)$ is illustrated by the next equation for [4ph-TAzole]: $\lambda_{\text {Cal. }}=0.973 \lambda_{\text {Exp. }}+9.05$ with correlation coefficient $\left(\mathrm{R}^{2}=0.999\right)$.

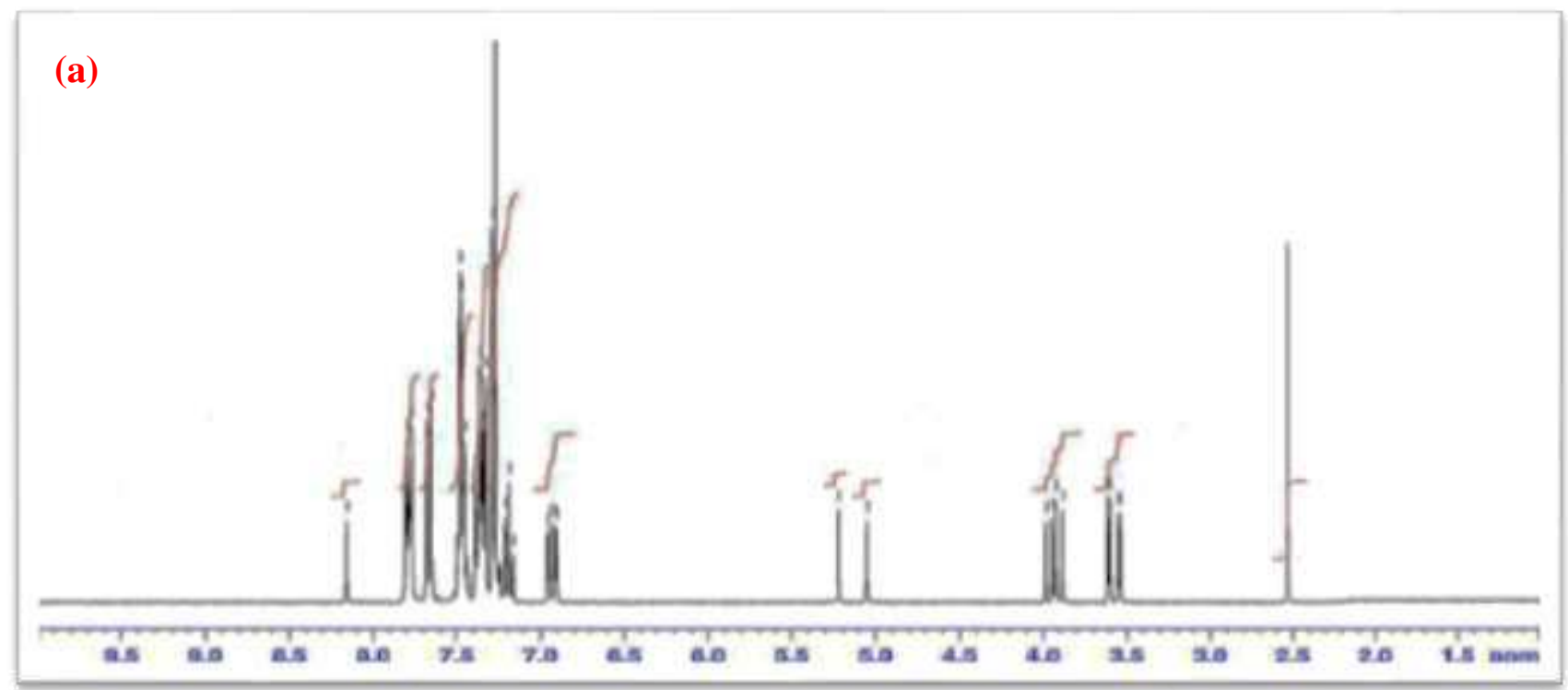

(b)
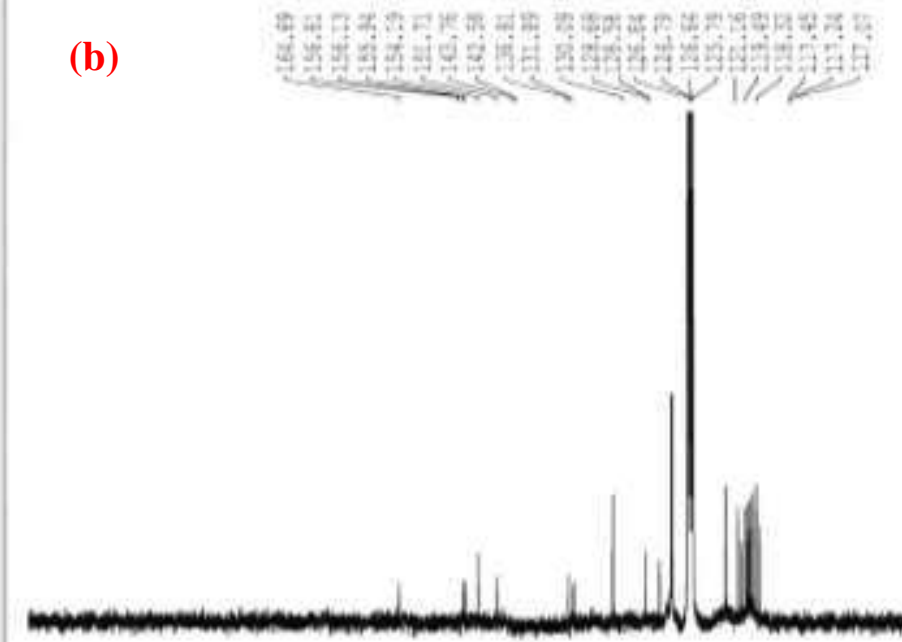

Fig. 2(a-b) Comparison of experimental and theoretical ${ }^{1}$ HNMR of [4ph-TAzole] isolated molecule in gaseous state.

\subsection{Mass Spectra}


Additional approving of the structure of the newly prepared dye [4ph-TAzole] dye, was obtained through its mass spectrum (Fig.3) that recorded an ion peak $\left(\mathrm{C}_{36} \mathrm{H}_{30} \mathrm{~N}_{10}\right)$ at $\mathrm{m} / \mathrm{z} 602.69\left(\mathrm{M}^{+}, 5\right)$. In conclusion, based on all the above spectroscopic data, the structure of the newly prepared 1,2,3-triazole dye [4phTAzole] (7) was entirely clarified.

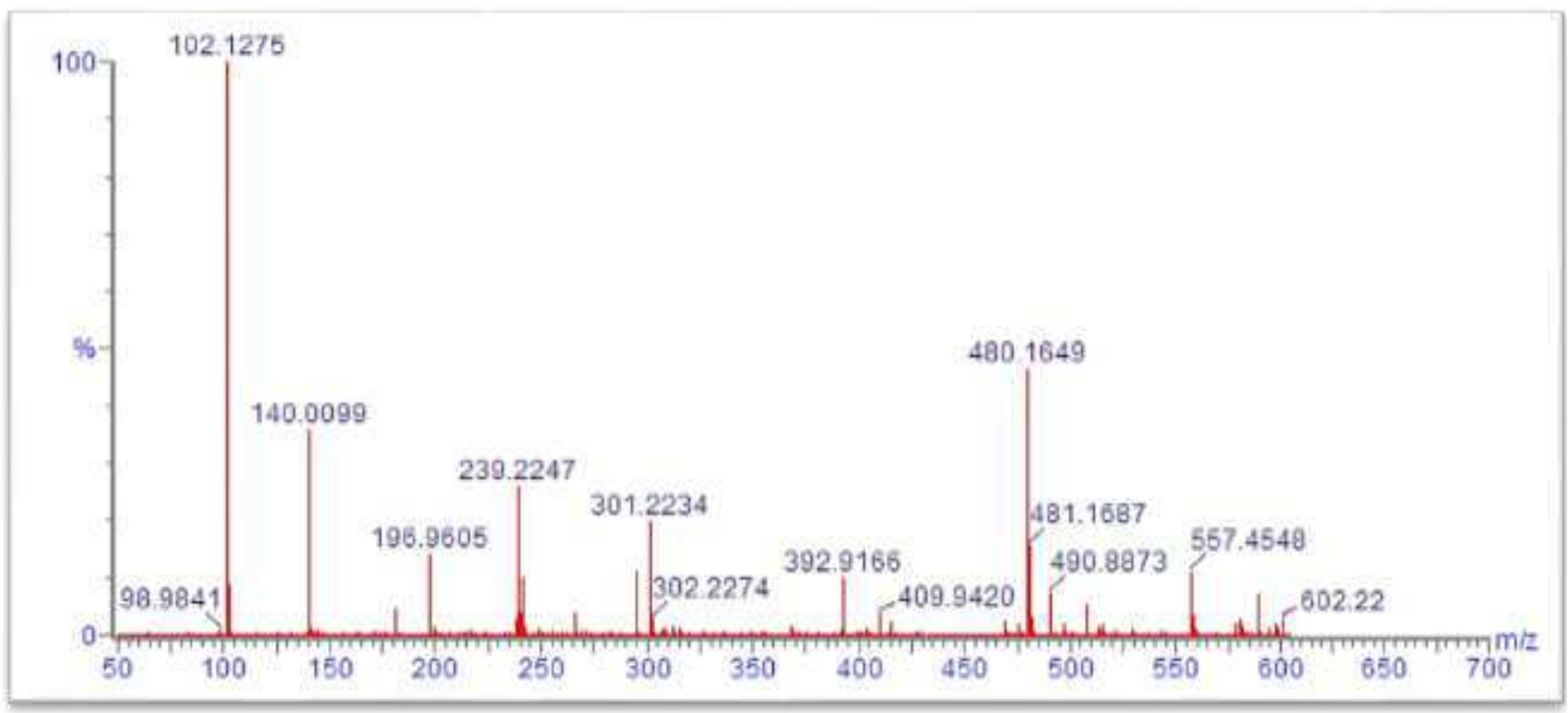

Fig. 3 The experimental data mass spectrum of [4ph-TAzole].

\subsection{XRD of [4ph-TAzole] $]^{\mathrm{TF}}$ thin film.}

Fig. 4 shows the pattern of XRD spectra for [4ph-TAzole $]^{\mathrm{TF}}$. It is observed that fabricated thin film is a polycrystalline in nature as many sharp peaks with different intensities were determined in a wavelength range $6 \mathrm{~nm} \leq \lambda \geq 45 \mathrm{~nm}$ demonstrating the fine crystallinity order of the material. The diffraction peaks of $[4 \mathrm{ph}-\mathrm{TAzole}]^{\mathrm{TF}}$ for the as-deposited thin film are determined with the help of CRYSFIRE computer program $[35,36]$. The values of the inter-planar spacing, d, Full Width at Half Maximum "FWHM", and Miller indices, hkl, for each peak are determined by using Kurt Barthelme's \& Bob Downs Software Program Refine Version 3.0 application [37] as listed in Table 1. 


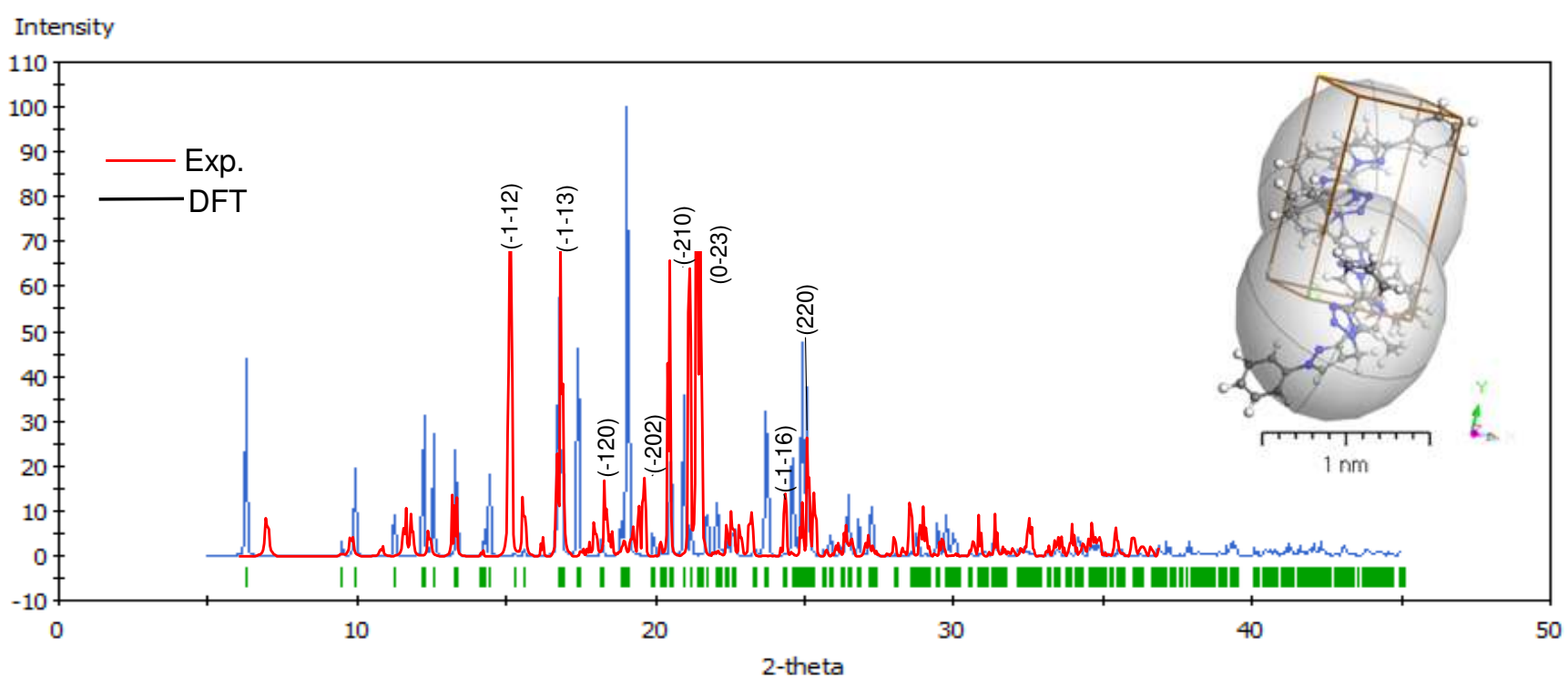

Fig. 4 Combined experimental and simulated XRD patterns for [4ph-TAzole] ${ }^{\mathrm{TF}}$ thin film

The crystallographic results show that both $[4 \mathrm{ph}-\mathrm{TAzole}]^{\mathrm{TF}}$ thin film and gas-phase has a TRICLINIC crystal structure according to database_code_amcsd 0001646 [38]. Crystal Sleuth Microsoft and Polymorph calculations system was used to measure the peak values shown on-line of diffraction. The lattice parameters are estimated as $\mathrm{a}=8.22(1) \AA, \mathrm{b}=8.71(2) \AA, \mathrm{c}=21.63(9) \AA$, while $\alpha=86.3(4)$; $\beta=$ 96.3(4),$\gamma=88.5(1)^{\circ}$, at the same time, the crystal volume is 1530(7) $\AA$. Also, from Fig. 5 it is clear that, the fabricated film is crystallized by a preferential orientation $(-1-12),(-1-13),(-202),(-120),(-210),(0-$ 23), (-1-16) and (220), at around $2 \theta$ of $16.8^{\circ}, 19.01^{\circ}, 22.61^{\circ}, 23.70^{\circ}, 24.57^{\circ}, 24.89^{\circ}, 28.73^{\circ}, 29.72^{\circ}$, respectively. The diffraction pattern exhibits multipeaks indicating that $[4 \mathrm{ph}-\mathrm{TAzole}]^{\mathrm{TF}}$ thin film is polycrystalline. Qualitative comparison depends on a visual evaluation indicates a good agreement between the calculated XRD for both Polymorphs and experimental patterns.

Table 1: The computed crystallinity parameters for $[4 \mathrm{ph}-\mathrm{TAzole}]^{\mathrm{TF}}$ at $\lambda=1.54 \AA$, machine error $=-0.199$.

\begin{tabular}{|c|c|c|c|c|c|c|c|c|c|c|}
\hline \multirow{2}{*}{ Compound } & \multicolumn{2}{|c|}{ Observed } & \multirow{2}{*}{ hkl } & \multicolumn{2}{|c|}{ Calculated } & \multicolumn{2}{|c|}{ DIFFERENCE } & \multirow{2}{*}{$\begin{array}{c}\text { Intensity } \\
\mathrm{PI}\end{array}$} & \multirow{2}{*}{ FWHM } & \multirow{2}{*}{$\mathrm{D}(\mathrm{nm})$} \\
\hline & $2 \theta$ & $d(\AA ̊)$ & & $2 \theta$ & $\mathrm{d}(\AA \AA)$ & $2 \theta$ & $\mathrm{d}(\hat{A})$ & & & \\
\hline \multirow{8}{*}{$\begin{array}{l}\text { Symmetry [4] } \\
\text { TRICLINIC } \\
a=8.22(1) ; b=8.71(2) ; \text { and } \\
c=21.63(9) \\
\alpha=86.3(4) ; \beta=96.3(4) \\
\text { and } \gamma=88.5(1)^{\circ} \\
\text { Volume }=1530(7) \\
\text { rmse }=0.000228^{*} \\
\text { Machine Error }=-\mathbf{0 . 1 9 9}\end{array}$} & 16.80 & 5.33 & $-1-12$ & 16.76 & 5.35 & -0.0459 & -0.0147 & 172.25 & 0.1912 & 43.90 \\
\hline & 19.01 & 4.71 & $-1-13$ & 19.06 & 4.70 & 0.0523 & 0.01294 & 130.71 & 0.1612 & 52.23 \\
\hline & 22.61 & 3.96 & -202 & 22.60 & 3.97 & -0.0088 & -0.0015 & 35.65 & 0.1412 & 59.97 \\
\hline & 23.70 & 3.78 & -120 & 23.70 & 3.78 & 0.0012 & 0.00019 & 115.07 & 0.1534 & 55.31 \\
\hline & 24.57 & 3.65 & -210 & 24.58 & 3.65 & 0.0048 & 0.00071 & 370.07 & 0.0574 & 148.05 \\
\hline & 24.89 & 3.60 & $0-23$ & 24.89 & 3.60 & -0.0054 & -0.0008 & 474.42 & 0.0273 & 311.48 \\
\hline & 28.73 & 3.13 & $-1-16$ & 28.73 & 3.13 & -0.0038 & -0.0004 & 53.81 & 0.0596 & 143.82 \\
\hline & 29.72 & 3.02 & 220 & 29.71 & 3.02 & 0.0015 & 0.00015 & 103.79 & 0.0624 & 137.68 \\
\hline Average & & 3.8975 & & & 3.9 & & $2.5 \times 10^{-3}$ & & 0.1067 & 119.06 \\
\hline
\end{tabular}


The microstructure parameters like grain size, crystal strain, and dislocation density have been calculated. The average crystallite size, $\mathrm{D} \mathrm{nm}$, of $[4 \mathrm{ph}-\mathrm{TAzole}]^{\mathrm{TF}}$ thin films was calculated for the most intense broadening peaks using Scherer's formula [39] as list in Table 1:

$$
D=\frac{k \lambda}{\beta \cos \theta}
$$

Where $\lambda$ is the wavelength of the X-ray used $(1.54 \mathrm{~nm}), \beta$ is the full width at half maximum (FWHM in radians) of the diffraction peak in radians, $\theta$ is the corresponding Bragg angle, and $\mathrm{k}$ is a constant nearly equal 0.9 . The lattice strain, $\varepsilon$, is calculated by using the following relation [40]:

$$
\varepsilon=\frac{\beta}{4 \tan \theta}
$$

The dislocation density, $\mathrm{d}$, can be defined as the length of the dislocation lines per unit volume of the crystal. It is calculated from the formula [41]:

$$
\delta=\frac{1}{D^{2}}
$$

The average estimated crystallite sizes of the as-deposited thin film [4ph-TAzole] ${ }^{\mathrm{TF}}$ was $119.06 \mathrm{~nm}$. While the average lattice strain $\varepsilon_{\text {ave. }}$ was found to be 0.14216 , i.e, the crystallite is characterized by its large size. Moreover, the average dislocation density for the $[4 \mathrm{ph}-\mathrm{TAzole}]^{\mathrm{TF}}$ thin films was $2.05875 \times 10^{14} \mathrm{~m}^{-2}$.

The chemical and physical similarities of the gaseous phase for $[4 \mathrm{ph}-\mathrm{TAzole}]^{\mathrm{TF}}$ were studied utilizing electron density and electrostatic potential [42-44]. DFT-TDDFT fundamental principles (Fig. 5(a)), which utilize electron density as a significant operator for evaluating the ground status for [4ph-TAzole] ${ }^{\mathrm{TF}}$ gaseous phase electron systems. An image in Fig. 5(b) describes potential diagrams that display important growth prospects for [4ph-TAzole] ${ }^{\mathrm{TF}}$ gaseous phase potential. This supports the significant chance of electron transfer in the gas phase for $[4 \mathrm{ph}-\mathrm{TAzole}]^{\mathrm{TF}}$. The molecular electrostatic potential (MEP) has been employed to calculate the electrostatic potential in line with its surface density. The resulted image from Fig. 5(c) displays a 3D view of the active MEP site during the gas phase of the [4ph-TAzole] ${ }^{\mathrm{TF}}$. Blue and red colors indicate the favorable areas for nuclear and electrical attacks. In gaseous phase, the potential range $[\mathrm{P}]$ of the $[4 \mathrm{ph}-\mathrm{TAzole}]^{\mathrm{TF}}$ matrix is $4.30 \times 10^{-1} \geq[\mathrm{P}] \geq 1.167 \times 10^{-1}$, the color order: red < brown < blue [45]. Whilst red is a strong repudiation, Blue is a growing attraction [46]. The diagram of MEPs shows the possible negative regions where hydrogen atoms have a positive potential. 

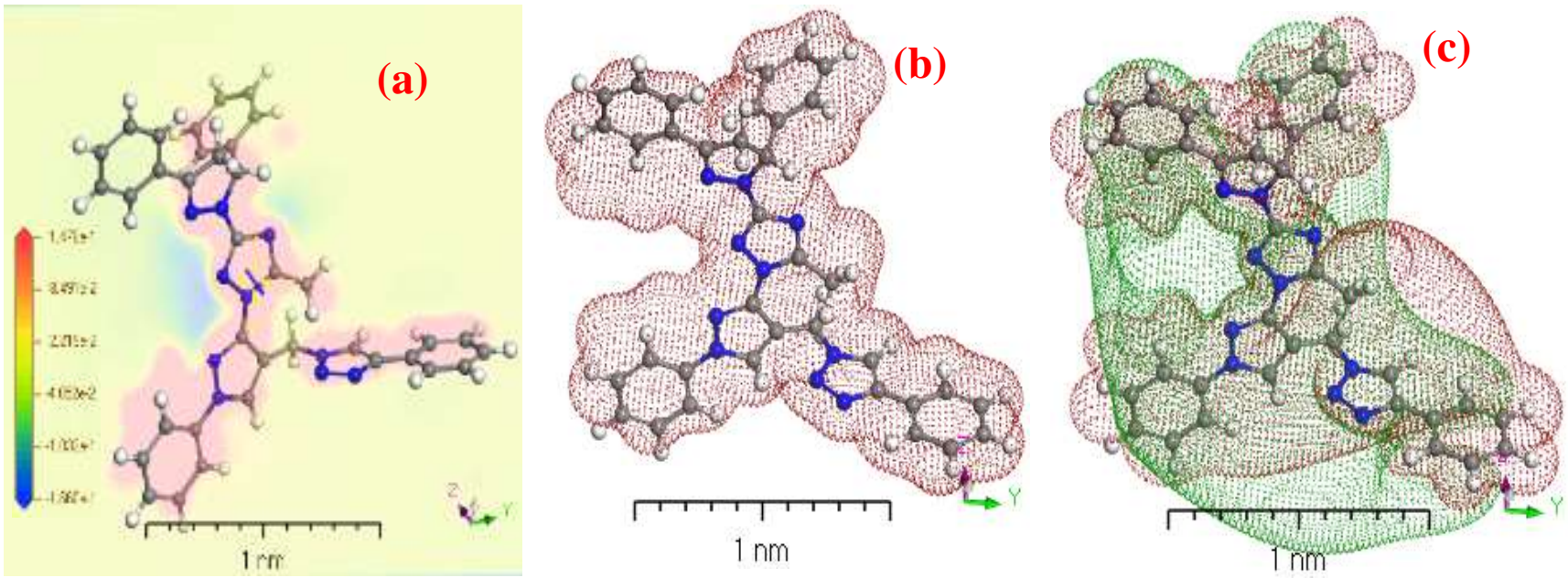

Fig. 5 a) MEP of [4ph-TAzole] gas phase, b) Electron density of [4ph-TAzole] gas phase and c) Potential of [4ph-TAzole] gas phase utilizing Gaussian software and DMOl${ }^{3} / \mathrm{DFT}^{\mathrm{p}}$ programs

\subsection{Optical Properties of the [4ph-TAzole $]^{\mathrm{TF}}$ thin film}

The spectral characteristics of absorbance (A) of [4ph-TAzole] ${ }^{\mathrm{TF}}$ thin film are depicted in Fig. 6(a-c). Fig. 6a shows the experimental absorbance spectrum characterized by only one main broad peak. Broad absorption Soret band at $\lambda_{\max }=352.23 \mathrm{~nm}$ (i.e., $h v_{\max }=3.5199 \mathrm{eV}$ ) has been obtained in a wavelength range $250 \mathrm{~nm} \leq \lambda \leq 450 \mathrm{~nm}$. Again, Fig.6a depicted that at $\lambda_{\max }=352.23 \mathrm{~nm}$ an absorption band maybe attributed to $n \rightarrow \pi^{*}$ electronic transition. The electronic transition of the $[4 \mathrm{ph}-\mathrm{TAzole}]^{\mathrm{TF}}$ thin film from HOMO (Highest Occupied Molecular Orbital) to LUMO (Lowest Unoccupied Molecular Orbital) is also connected to this absorption band at approximately $352.23 \mathrm{~nm}$ [47].
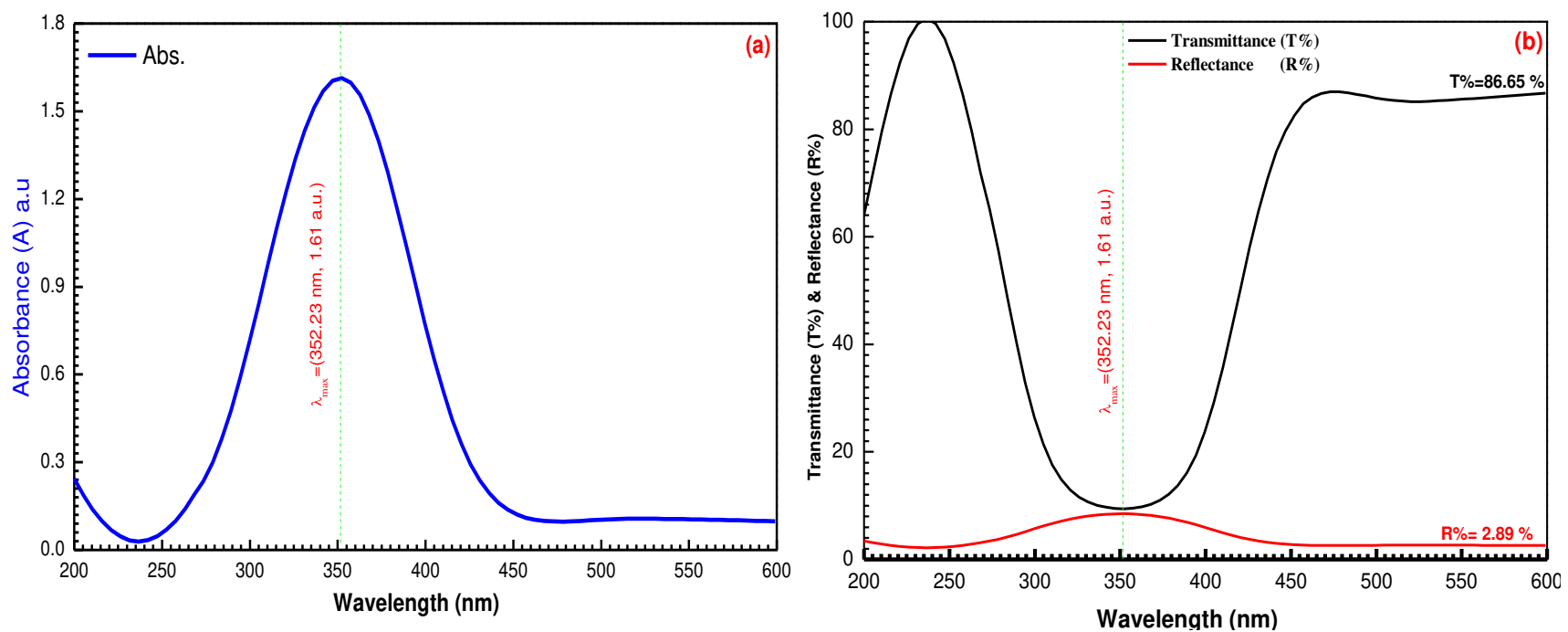


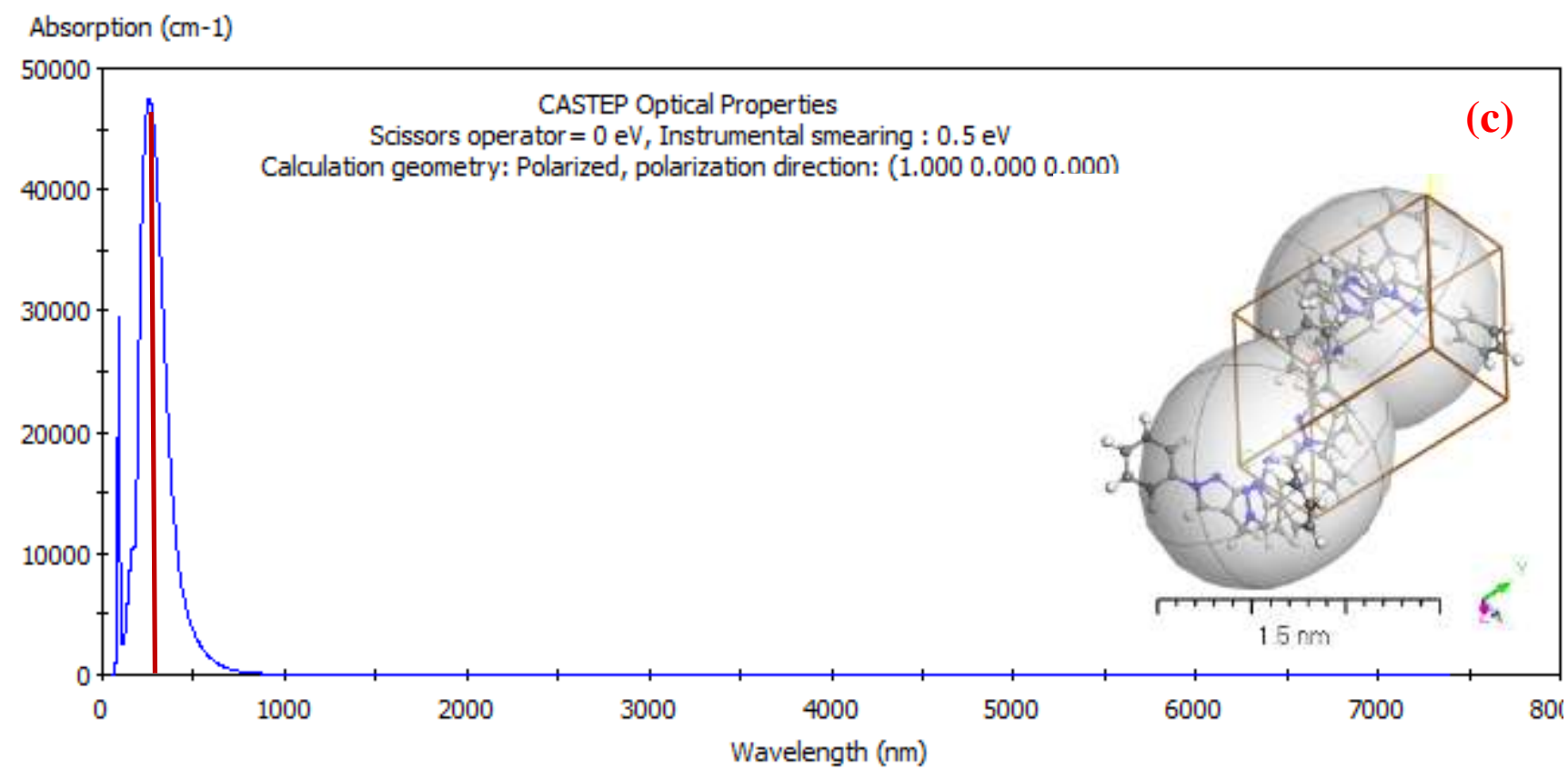

Fig. 6(a-b) Experimental absorbance (A); b) Experimental transmittance (T\%) and Reflectance (R\%) for the $[4 \mathrm{ph}-\mathrm{TAzole}]^{\mathrm{TF}}$. c) Simulated absorption for the thin film as-gas phase using CATSTEP/DFT.

Fig.6(b) show the spectral characteristics of transmittance $\mathrm{T}(\lambda)$ and reflectance $\mathrm{R}(\lambda)$ for [4ph-TAzole] ${ }^{\mathrm{TF}}$ thin films measured at normal incidence of light in the wavelength range $200 \mathrm{~nm} \leq \lambda \leq 600 \mathrm{~nm}$. From the figure the spectrum can be divided into three regions: i) first region at $200 \mathrm{~nm} \leq \lambda \leq 280 \mathrm{~nm}$. Since $\mathrm{T}(\lambda)+\mathrm{R}(\lambda)=1$ at $\lambda$ ranged from $225 \mathrm{~nm}$ to $250 \mathrm{~nm}$ and vice versa. The second region ii) at $280 \mathrm{~nm} \leq \lambda$ $\leq 445 \mathrm{~nm}$, the main absorption band, since sum of both $\mathrm{T}(\lambda)+\mathrm{R}(\lambda)<1$, which can be attributed to the existence of absorption or scattering of light originating from surface roughness of the formed film $[48,49]$. Finally, the third region iii) at $\lambda>450 \mathrm{~nm}$, the $[4 \mathrm{ph}-\mathrm{TAzole}]^{\mathrm{TF}}$ film exhibits high transmittances ( $\mathrm{T} \geq 86.65 \%)$. The film in this spectral region become transparent and no light is scattered or absorbed which known as non-absorbing region [50].

To explain the spectroscopic properties for [4ph-TAzole $]^{\mathrm{TF}}$ film a CATSTEP/DFT simulation technique is used. Fig. 6c illustrates (y-axis, absorption) versus (x-axis, wavelength) for [4ph-TAzole] matrix by applying CATSTEP/DFT computations at $0 \mathrm{~nm} \leq \lambda \leq 800 \mathrm{~nm}$. By comparison, the CATSTEP/DFT simulation method (Fig. 6c) and the experimental results of absorbance (Fig.6a), it can be concluded that, (i) the $n-\pi^{*}$ transition for [4ph-TAzole] gaseous molecule estimated from the DFT calculations and (ii) The HOMO-LUMO transition is based on the excitonic experimental peaks. a slightly shifted (i.e, decreasing) of HOMO-LUMO transition was observed from the absorption spectra of [4ph-TAzole] by CATSTEP/DFT simulation method. This maybe attributed to an atomic surface state resulting from organized sites in [4ph-TAzole] the gaseous process $[51,52]$.

The theory of energy bands is an interesting way of visualizing differences between conductors, insulators and semiconductors. The bandgap is the energy disparity between the valence bands and the 
substance conduction bands. Usually, the optical band gap can be calculated from the analysis of the spectral dependence of the absorption near the fundamental absorption edge. The absorption coefficient $\alpha$ is well described by the following relation [53]:

$$
(\alpha h v)=B\left(h v-E_{g}\right)^{m}
$$

Where $h v$ is the energy of the incident photons and the factor B is a constant depends on the transition probability among the optical frequency range, and an energy independent constant having values between $1 \times 10^{5}$ and $1 \times 10^{6}(\mathrm{~cm} . \mathrm{eV})^{-1}[54,55]$.

The absorption coefficient $(\alpha)$ was determined with the expression $\alpha=\mathrm{Abs} . / \mathrm{d}$, where $\mathrm{d}$ is the computed thin film thickness. While $E_{g}$ is the value of the optical band gap corresponding to transitions indicated by the value of $(\mathrm{m})$. For the direct and indirect transformations allowed respectively $\mathrm{m}$ values of 2 and $1 / 2$ is assumed [56-58]. The allowed direct values of $E_{g}$ (direct) optical band gaps were computed by extrapolating the plots linear portion of $(\alpha h v)^{2}$ (y-axis) vs. $h v$ and that $(\alpha h v)^{0.5}$ (y-axis) vs. $h v$ when $\mathrm{y}$-axis $=0$.

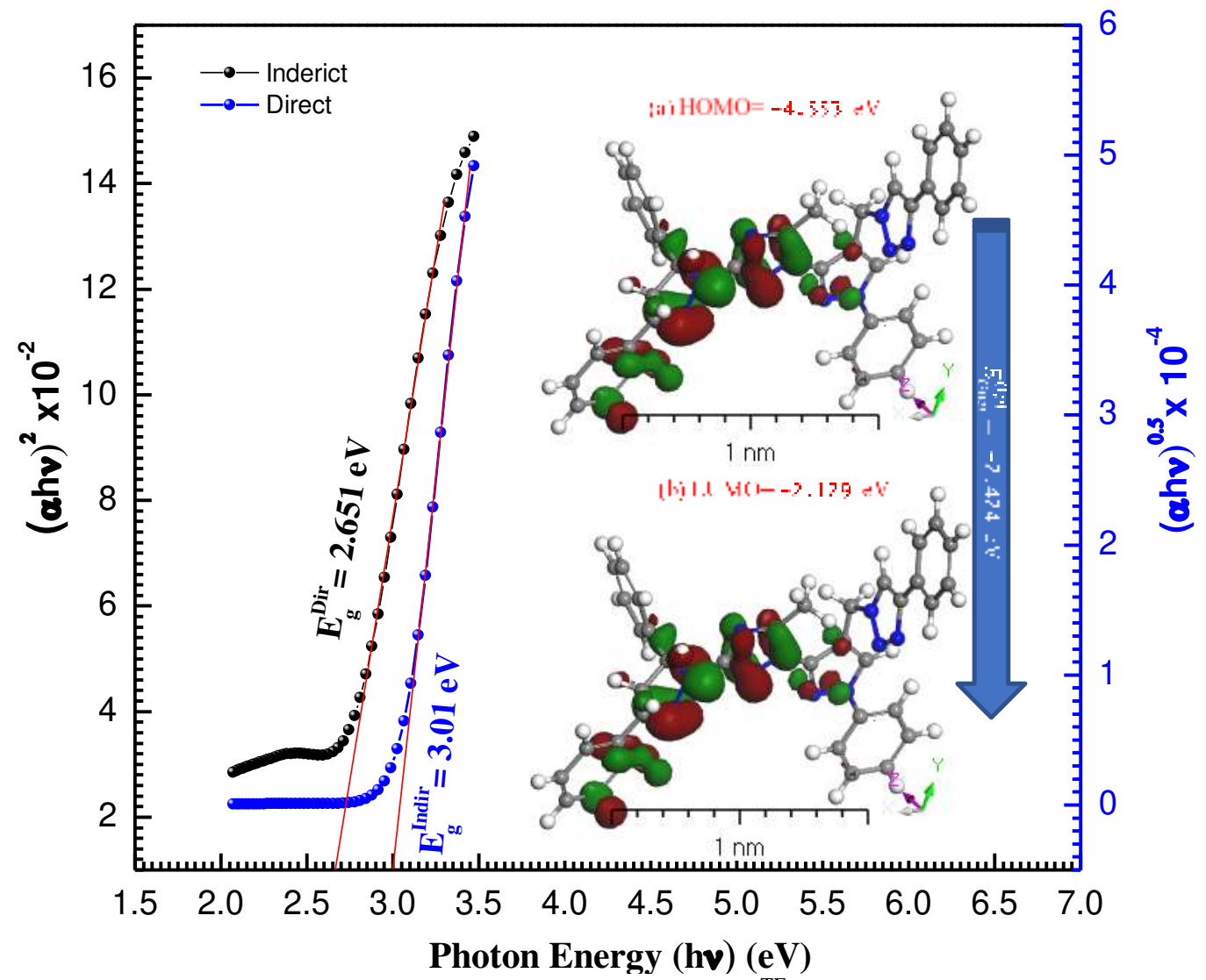

Fig. 7. Plot $(\alpha h v)^{m}$ vs photon energy $(h v) \mathrm{eV}$ for [4ph-TAzole] ${ }^{\mathrm{TF}}$ thin film, inset figure HOMO \& LUMO simulation of [4ph-TAzole] by using $\mathrm{DMol}^{3}$ method in DFT.

Fig. 7 shows the plot of the experimental results of both $(\alpha h v)^{2}$ and $(\alpha h v)^{0.5}$ vs. $(h v)$ for [4phTAzole $]^{\mathrm{TF}}$ nanostructure thin film. The energy band gap values for $[4 \mathrm{ph}-\mathrm{TAzole}]^{\mathrm{TF}}$ is $\left(E_{g}^{\text {Direct }}=2.651\right.$ 
$\mathrm{eV}$ ) is calculated as listed in Table 2, since the [4ph-TAzole $]^{\mathrm{TF}}$ thin film is in the semiconductor materials range. While $E_{g}^{\text {Direct }}=3.01 \mathrm{eV}$ for indirect energy gap. Also, Fig.7 (inset) depicts DFTs simulation by utilizing $\mathrm{DMol}^{3}$, the $E_{g}^{\text {Direct }}=$ value for [4ph-TAzole] ${ }^{\mathrm{TF}}$ thin films is $2.424 \mathrm{eV}$ listed in Table 2. Also, the HOMO and LUMO simulation shown in Fig. 7 (inset) indicates an agreement of the direct energy gap values calculated by Tauc's equation with a small difference in values $\left(\Delta E_{g}^{\text {Direct }}=0.227 \mathrm{eV}\right)$, while that for indirect energy gap $\left(\Delta E_{g}^{\text {Indirect }}=0.586 \mathrm{eV}\right)$. By using Frontier Molecular Orbitals (FMO's) utilizing the generalized gradient approximation GGA/PW91method, 3D HOMO and LUMO plots for [4phTAzole] as- single crystal as shown in Fig. 7 (inset). A localization of EHOMO at $-4.553 \mathrm{eV}$ (on iodide ions) and ELUMO at $-2.129 \mathrm{eV}$ (are spreading over the coordinated thiobarbituric) [59].

The refractive $n(\lambda)$ index and extinction coefficient $\mathrm{k}(\lambda)$ of [4ph-TAzole] ${ }^{\mathrm{TF}}$ thin film, in a photon energy range from $2.0 \mathrm{eV}$ to $6.50 \mathrm{eV}$ was determined from the measured transmittance and reflectance at normal light incidence. The spectral dependences of both $n(\lambda)$ and $k(\lambda)$ are plotted in Fig. 9(a). The absorption index $\mathrm{k}$ is so small at $4.6 \mathrm{eV}<\mathrm{hv}<2.75 \mathrm{eV}$, showing that the prepared film is highly transparent in these regions. The decrease of $\mathrm{k}(\lambda)$ may be attributed to light scattering and decrease of absorbance [60]. Also, it is observed that, in $\mathrm{k}(\lambda)$ has a broad absorption band with a maximum value of $k_{\max }=$ $1.55 \times 10^{-8}$ at $h v=3.47 \mathrm{eV}$. This peak of extinction index is due to the characteristic feature of existence of free carriers [61].

As for $\mathrm{n}(\lambda)$ has the same behavior as $\mathrm{k}(\lambda)$ a characteristic broad peak in at $2.70 \mathrm{eV}<\mathrm{hv}<5.25 \mathrm{eV}$ corresponding to the ultraviolet and visible spectral regions are observed. Also, this broad peak is featured by a double splitting with maximum value of refractive index $n_{\text {max }}=1.6$ at two different photon energies of 3.15 and $3.9 \mathrm{eV}$. This splitting of $\mathrm{n}(\lambda)$ can be explained using multi-oscillator model. At the same time, at photon energy $2.5 \mathrm{eV} \geq h v \geq 5.25 \mathrm{eV}$, the spectral behavior of $\mathrm{n}(\lambda)$ indicates a normal dispersion which can be explained by adopting single oscillator model. In some applications such as optoelectronic devices, such as switches, solar cells, filters and modulation, the evaluation of the refractive indices of optical materials is considerably important, in which the refractive index is a key parameter for the device design [62]. 

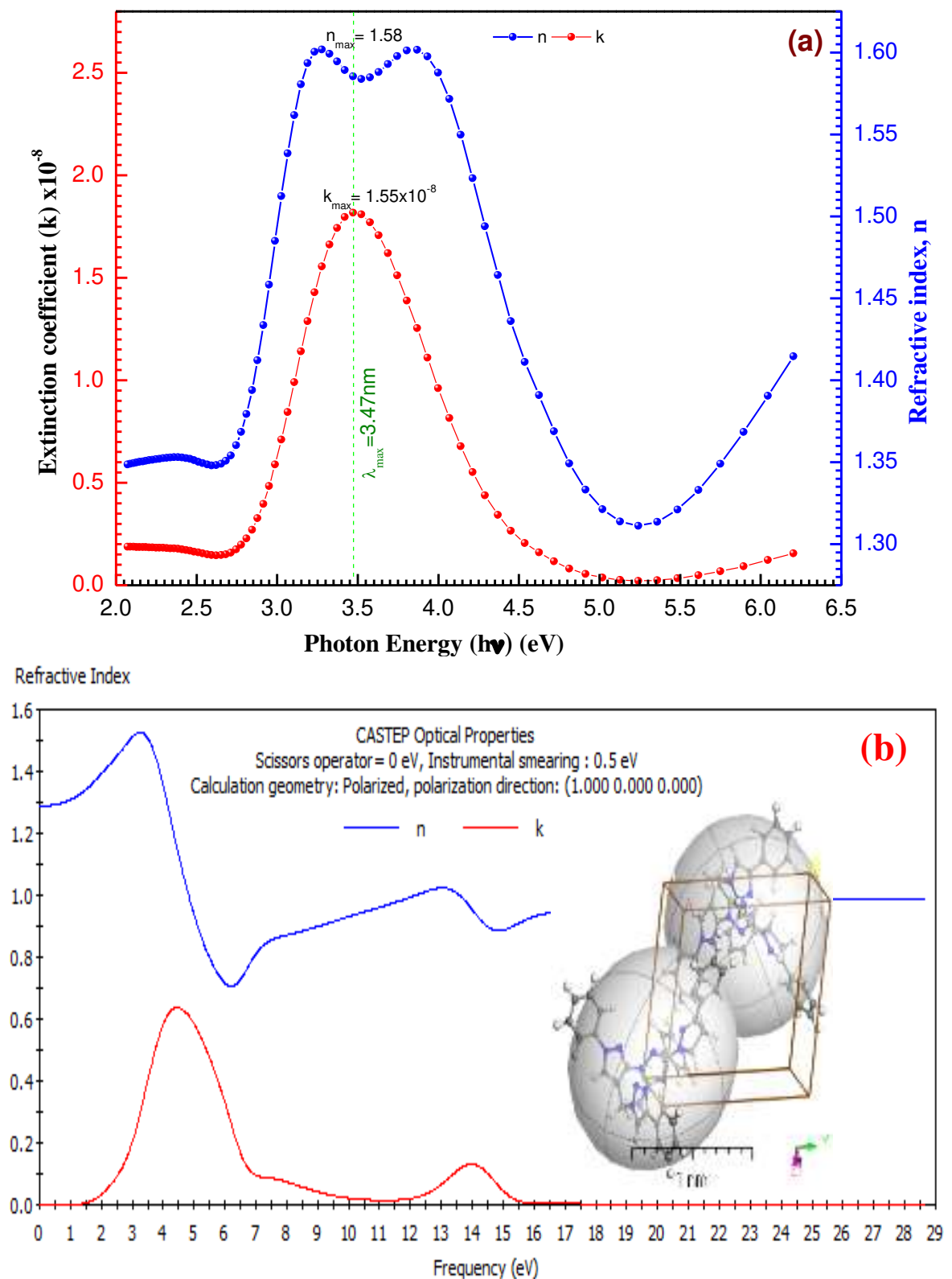

Fig. 8. a) Plot $(n)$ and $(k)$ vs photon energy $(h v)$ eV for [4ph-TAzole] ${ }^{\mathrm{TF}}$ as-deposited thin films, b) $(n)$ and $(k)$ vs photon energy $(h v) \mathrm{eV}$ simulation of [4ph-TAzole $]^{\mathrm{TF}}$ using CASTEP/DFT-TDDFT.

The simulation by using CASTEP/DFT-TDDFT of [4ph-TAzole] as-single crystal was used to expect the maximum $\mathrm{n}(\lambda)$ and $\mathrm{k}(\lambda)$ values at $\mathrm{h} v(\mathrm{eV})$ (as shown in Fig. 9b). It is also necessary to notice that the simulation curve shown in Fig. $8 \mathrm{~b}$ indicates an overall resemblance with a minor shift of the maximum energies of [4ph-TAzole] with lower peak intensities for $n(\lambda)$ and $\mathrm{k}(\lambda)$.

According to the single oscillator model, the dispersion curve can be explained using the dispersion $\left(E_{d}\right)$ and oscillating energy $\left(E_{0}\right)$ in the high wavelength region, using the Wemple-DiDomenico formula [63]:

$$
\left(n^{2}-1\right)^{-1}=\frac{E_{0}}{E_{d}}-\frac{1}{E_{0} E_{d}}(h v)^{2}
$$

According to Eq.(4), the $\left(n^{2}-1\right)^{-1}$ is represented as a function of photon energy and shown in Fig.9(a). The normal dispersion parameters, $E_{d}, E_{0}$, can be estimated from both the slope and the intercept of a linear fit to the high-frequency region and listed in Table 2. 
On one hand, the high frequency dielectric constant is connected with the contribution of the electronic polarization mechanism to the total dielectric response of [4ph-TAzole] ${ }^{\mathrm{TF}}$ thin films [64]. The oscillator strength (f) is given by using the following relation [65]:

$$
f=E_{0} E_{d}
$$

The value of $\mathrm{f}$ was calculated for [4ph-TAzole] $]^{\mathrm{TF}}$ thin films and listed in Table 2. Obtained values of $\mathrm{f}$ are found to be high as compared with those values published by $[66,67]$. This may be attributed to the higher oscillator energy value of [4ph-TAzole $]^{\mathrm{TF}}$ thin films prepared by PVD.
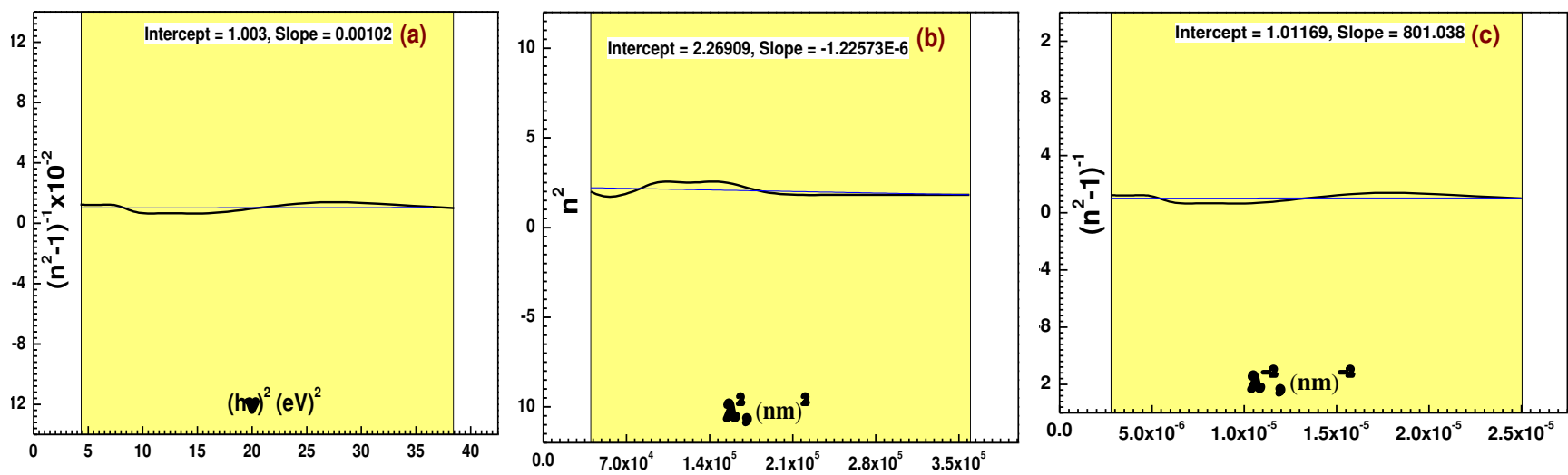

Fig. 9: $\left(n^{2}-1\right)^{-1} v s(h v)^{2}, n^{2}$ vs $\lambda^{2}$ and $\left(n^{2}-1\right)^{-1} v s \lambda^{-2}$ plots for [4ph-TAzole] $]^{\mathrm{TF}}$ as-deposited thin films.

Table 2: Characteristic optical parameters for [4ph-TAzole $]^{\mathrm{TF}}$ films.

\begin{tabular}{|c|c|c|c|c|c|c|c|c|c|c|}
\hline $\mathrm{E}_{\mathrm{d}}(\mathrm{eV})$ & $\mathrm{E}_{\mathrm{o}}(\mathrm{eV})$ & $E_{g}^{o p t .}(\mathrm{eV})$ & $\Delta E_{g}^{O p t}$ & $\mathrm{M}_{-1}$ & $\mathrm{M}_{-3}(\mathrm{eV})^{2}$ & $f(e V)^{2}$ & $\begin{array}{l}\left(\mathrm{n} / \mathrm{m}^{*}\right) \\
\left(\mathrm{kg}^{-1}, \mathrm{~m}^{3}\right)\end{array}$ & $\lambda_{0}(\mathrm{~nm})$ & $\mathrm{S}_{0}\left(\mathrm{~nm}^{-1}\right)$ & $\begin{array}{l}\mathrm{E}_{\mathrm{o}} / \mathrm{S}_{0} \\
(\mathrm{eV} . \mathrm{nm})\end{array}$ \\
\hline 31.26 & 31.36 & $2.651^{\mathrm{a}} \quad 2.424^{\mathrm{b}}$ & 1.99 & 0.997 & 0.001 & 980.39 & $1.5 \mathrm{E}+39$ & 279.76 & $1.26 \mathrm{E}+13$ & $2.48 \mathrm{E}-12$ \\
\hline
\end{tabular}

a: experimental value of $E_{g}^{o p t .},{ }^{\text {b: }}$ by using simulation $\mathrm{DMol}^{3}$ method in DFT.

Another important relation, to estimate the high-frequency dielectric constant as follows:

$$
n^{2}=\varepsilon_{\infty}-\left\{e^{2} N / 4 \pi^{2} \varepsilon_{0} c^{2} m^{*}\right\} \lambda^{2}
$$

The relationship of $n^{2}$ vs. $\lambda^{2}$ is shown in Fig. 9(b). The slope and the extrapolation of the obtained linear fit can be used to calculate both the ratio $\left(N / m^{*}\right)$ and $\varepsilon_{\infty}$, respectively, and tabulated in Table 2 .

Moreover, there are two important moments like $M_{-1}$ and $M_{-3}$ which are related to single-oscillator parameters $\left(E_{0}\right.$ and $\left.E_{d}\right)$ and they are calculated using the following two relations $[68,69]$ :

$$
\begin{aligned}
& E_{0}^{2}=\frac{M_{-1}}{M_{-3}} \\
& E_{d}^{2}=\frac{M_{-1}^{3}}{M_{-3}}
\end{aligned}
$$

To identify a single oscillator approximation to the dielectric response of the material and find the average bond strength, these moments are estimated. In addition, these optical moments are related the macroscopic quantities like effective dielectric constant, effective number of valence electrons in the 
investigated material [70]. The calculated values of $M_{-1}$ and $\mathrm{M}_{-3}$ of [4ph-TAzole] ${ }^{\mathrm{TF}}$ thin films are listed in Table 2. The low values of $\mathrm{M}_{-1}$ and $\mathrm{M}_{-3}$ give indication for low polarization of the studied material [71].

Single Sellmeier oscillator at low energies can be used to determine the average interband oscillator wavelength $\left(\lambda_{0}\right)$ and the average oscillator strength $\left(\mathrm{S}_{0}\right)[72]$ can be obtained from:

$$
\left(n^{2}-1\right)^{-1}=\frac{1}{s_{0} \lambda_{0}^{2}}-\frac{1}{s_{0}}(\lambda)^{-1}
$$

Since $\lambda_{0}$ and $S_{0}$ values can be obtained from the slope and intercept of plotting $\left(n^{2}-1\right)^{-1}$ against $(\lambda)^{-1}$ curve as shown in Fig. 9c and tabulated in Table 2.

The value of refractive index is directly related to another fundamental quantity i.e., the complex dielectric constant $\left(\check{\varepsilon}=\varepsilon_{1}+\mathrm{j} \varepsilon_{2}\right)$ as [73]:

$$
\varepsilon_{1}=\mathrm{n}^{2}-\mathrm{k}^{2}
$$

and

$$
\varepsilon_{2}=2 \mathrm{nk}
$$

Since $\varepsilon_{1}$ and $\varepsilon_{2}$ are the real and imaginary parts of the dielectric constant. These dielectric constants are basically used to explain the linear response of system to incident electromagnetic radiations i.e., interaction of system with photons. Fig.10a shows that the experimental results of both real and imaginary parts of dielectric constant follow the same pattern for [4ph-TAzole] ${ }^{\mathrm{TF}}$ thin films. Also, from Fig.10a, it is concluded that: i) the values of $\varepsilon_{1} \gg \varepsilon_{2}$ and ii) $\varepsilon_{1}$ has the same spectral pattern as refractive index (n) while $\varepsilon_{2}$ as the extinction coefficient $(\mathrm{k})$. Since $\varepsilon_{1}$ is characterized by a principle double splitting broad peak in a photon energy range $2.70 \mathrm{eV} \leq \mathrm{hv} \leq 5.25 \mathrm{eV}$. While $\varepsilon_{2}$ is characterized by a single broad peak at the same photon energy range. In addition, the variation of the dielectric constant vs. photon energy indicates the interaction between photons and electrons in the films, in this energy range, which affect the shapes of the real and imaginary parts of the dielectric constant . They cause the formation of peaks in the dielectric spectra which depends on the material type [73].

Fig. 10b illustrates the estimated values of the dielectric constant of [4ph-TAzole] by using CASTEP simulation method. By comparing the experimental and simulation results in the photon energy range from $1.0 \mathrm{eV} \leq \mathrm{hv} \leq 6.5 \mathrm{eV}$, there is a good agreement of them with a slight upward shift in the photon energy, especially for the imaginary dielectric constant $\left(\varepsilon_{2}\right)$. Also, an increase in the dielectric function intensity has been observed. 


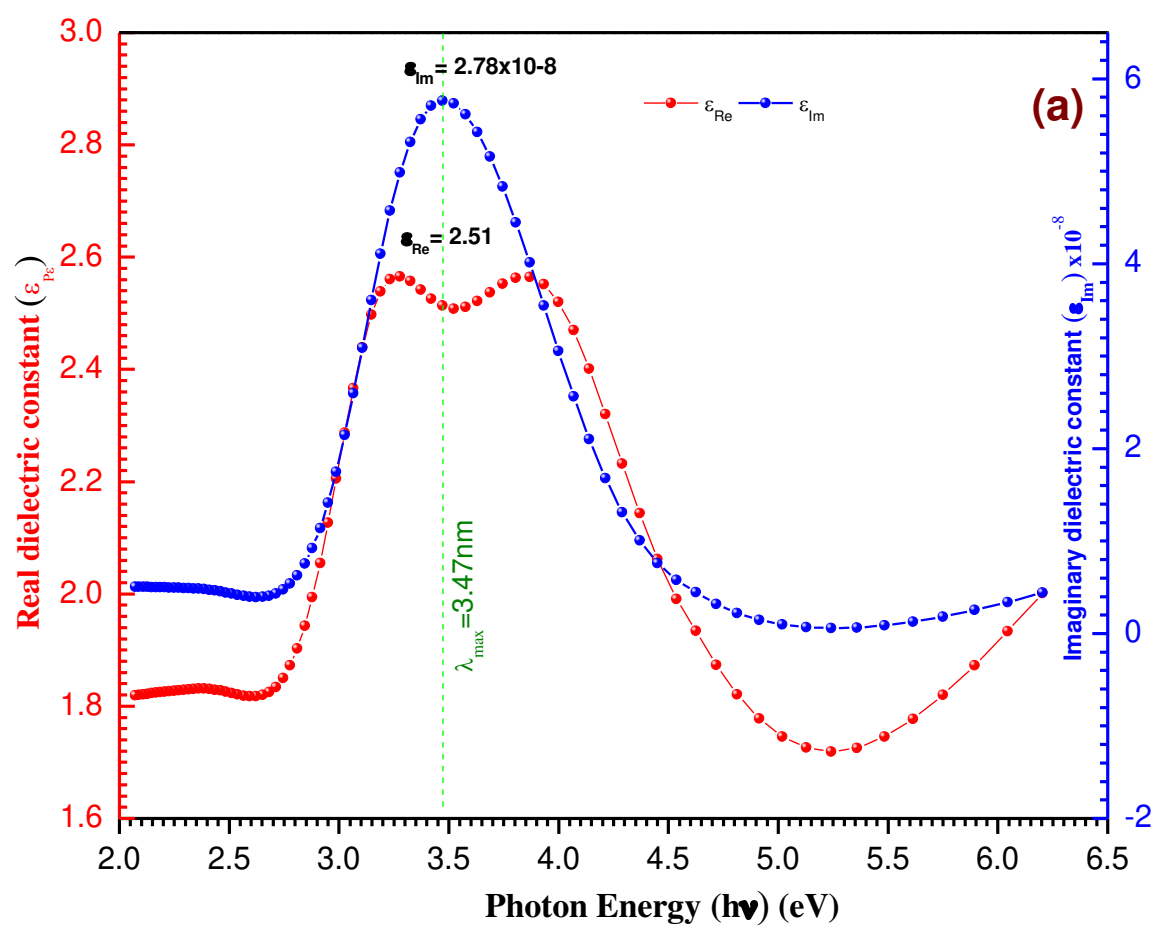

Dielectric Function

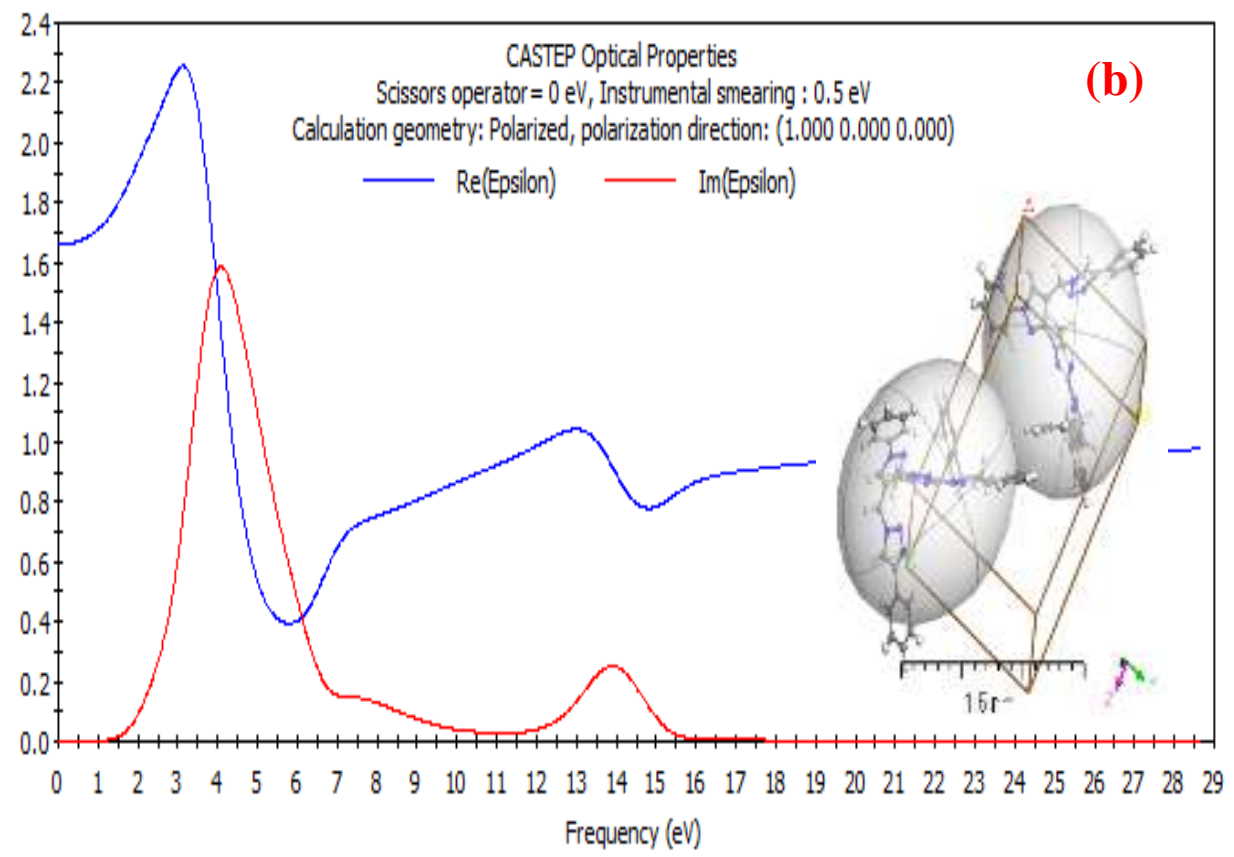

Fig. 10. a) $\left(\varepsilon_{\mathrm{Re}}\right)$ and $\left(\varepsilon_{\mathrm{Im}}\right)$ vs $(\mathrm{hv}) \mathrm{eV}$ for $[4 \mathrm{ph}-\mathrm{TAzole}]^{\mathrm{TF}}$ thin film. b) Simulation dielectric function for [4phTAzole] by using CASTEP method.

The real $\left(\sigma_{1}\right)$ and imaginary $\left(\sigma_{2}\right)$ parts of optical conductivity are related to the dielectric by the following [74]:

$$
\sigma_{1}=\omega \varepsilon_{0} \varepsilon_{2} \text { and } \sigma_{2}=\omega \varepsilon_{0} \varepsilon_{1}
$$

The photon energy dependence of both $\sigma_{1}$ and $\sigma_{2}$ is determined using the dielectric constants. Since $\omega=$ $2 \pi \mathrm{v}$, the angular frequency and $\varepsilon_{0}$ is the permittivity of free space. The obtained results of such optical conductivity are related to the characteristics of electronic structure and indicate the availability in the field of optoelectronic application. Fig. 11a shows the experimental results of both $\sigma_{1}$ and $\sigma_{2}$ versus 
photon energy (i.e, ranged as $2.0 \mathrm{eV} \leq \mathrm{hv} \leq 6.25 \mathrm{eV}$ ) of $[4 \mathrm{ph}-\mathrm{TAzole}]^{\mathrm{TF}}$ thin films. As observed from Fig.11a, shows that $\sigma_{1} \ll \sigma_{2}$ and the real part of the optical conductivity $\sigma_{1}$ has the spectral behavior as that for imaginary part of the dielectric constant $\varepsilon_{2}$. Since $\sigma_{1}$ spectrum is characterized by a single broad peak in a photon energy range $2.7 \mathrm{eV} \leq \mathrm{hv} \leq 5.2 \mathrm{eV}$. While $\sigma_{2}$ spectral pattern is characterized by a nonGaussian broad peak in a photon energy range $2.7 \mathrm{eV} \leq \mathrm{hv} \leq 5.2 \mathrm{eV} . \sigma_{1}$ and $\sigma_{2}$ peaks of [4ph-TAzole] ${ }^{\mathrm{TF}}$ films maybe attributed to the optical interband transitions [75].

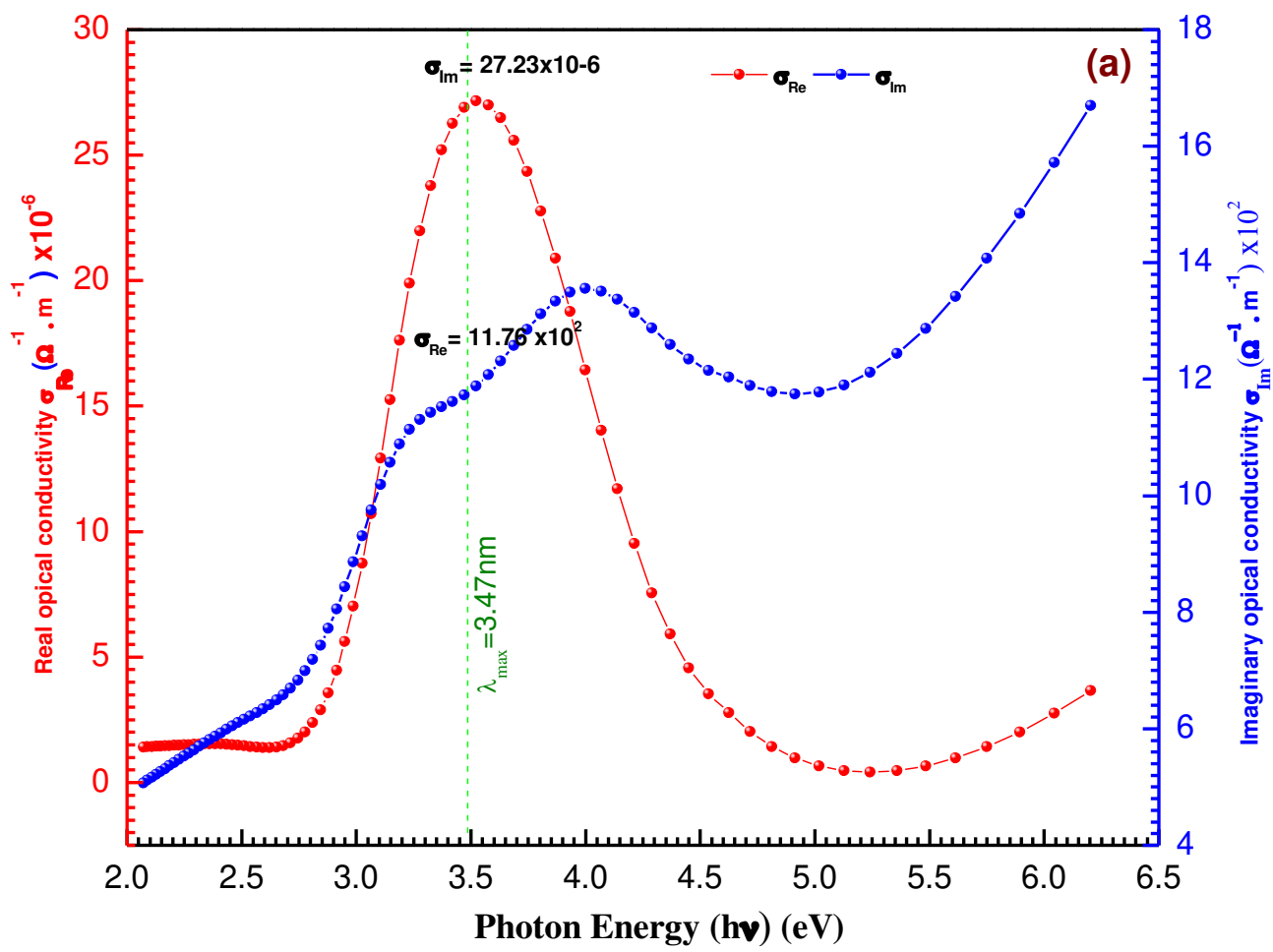

Conductivity $(1 / \mathrm{s})$

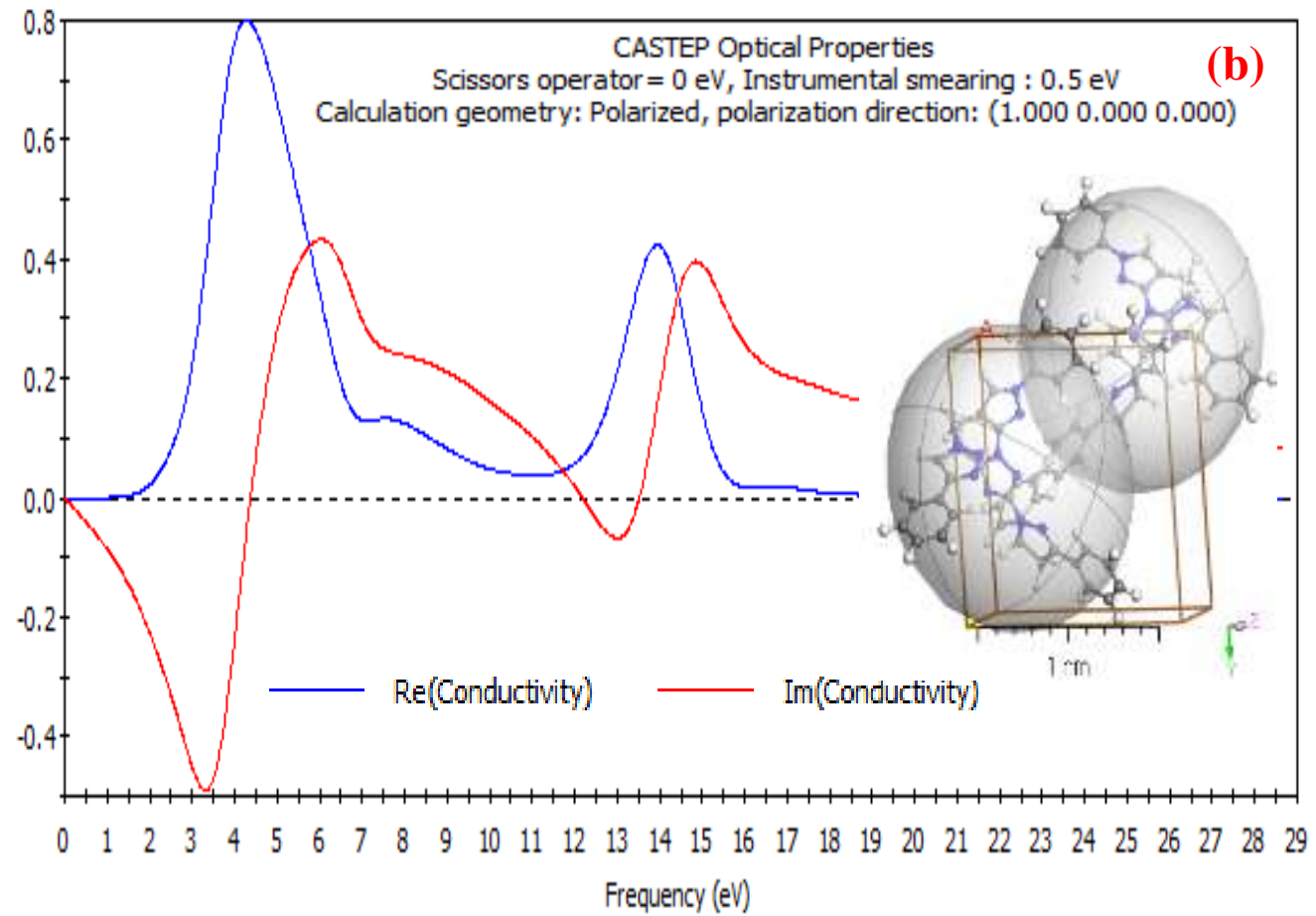

Fig. 11. a) $\left(\sigma_{\mathrm{Re}}\right)$ and $\left(\sigma_{\mathrm{Im}}\right)$ vs $(\mathrm{hv}) \mathrm{eV}$ for [4ph-TAzole $]^{\mathrm{TF}}$ thin film. b) Simulation conductivity function for [4ph-TAzole] by using CASTEP method. 
Fig. 11b shows the simulation optical conductivity of [4ph-TAzole] as-single crystal by using CASTEP method vs photon energy.

\section{Conclusions}

A conjugated semiconductor organic compound of 1-((3-(3-(3,5-diphenyl-4,5-dihydro-1H-pyrazol-1-yl)5-methyl-1H-1,2,4-triazol-1-yl)-1-phenyl-1H-pyrazol-4-yl)methyl)-4-phenyl-1H-1,2,3-triazole was synthesized via $\mathrm{Cu}$-catalyzed azide-alkyne cycloaddition reactions. Thin film with a thickness of $150 \pm$ $3 \mathrm{~nm}$ of the organic compound was manufactured by physical vapor deposition technique.The thin film was characterized using different techniques includes FTIR, UV-Vis, ${ }^{1} \mathrm{HNMR}, \mathrm{XRD}$, and mass spectra. The obtained DFT-TDDFT data provide good proof for the electronic transition in zero-dimensional [4ph-TAzole] ${ }^{\mathrm{TF}}$ as a single crystal molecule. Application Davis's and Shilliday's equation on [4ph-

TAzole] ${ }^{\mathrm{TF}}$ mentioned that the $\mathrm{E}_{\mathrm{g}}^{\mathrm{Dir}}$ and $\mathrm{E}_{\mathrm{g}}^{\mathrm{Ind}}$ transitions can be computed by plotting $(\alpha \mathrm{h} v)^{2}$ and $(\alpha \mathrm{h} v)^{0.5}$ versus hv nearby the value of fundamental band edge $\left((\alpha h v)^{2}\right.$ and $(\alpha h v)^{0.5}$ parts) in the computed Abs. $(\lambda)$ curves to zero absorption value, respectively. The direct and indirect energies were $1.983 \mathrm{eV}$ and 2.121 $\mathrm{eV}$ for thin film, respectively. The obtained thin film presents a promising result to be a good candidate for organic derivate of triazole solar cell applications.

\section{Acknowledgments}

I. H. El Azab thanks Taif University Researchers Supporting Project number (TURSP-2020/27), Taif University, Taif, Saudi Arabia. 


\section{References}

[1] Cerneaux, S.; Zakeeruddin, S. M.; Pringle, J. M.; Cheng, Y.; Grätzel, M.; Spiccia, L.Adv. Funct. Mater. 2007, 17, 3200.

[2] Kay, A.; Grätzel, M. Chem. Mater. 2002, 14, 2930.

[3] Nazeeruddin, M. K.; Péchy, P.; Renouard, T.; Zakeeruddin, S. M.; Humphry-Baker, R.; Comte, P.; Liska, P.; Cevey, L.; Costa, E.; Shklover, V.; Spiccia, L.; Deacon, G. B.; Bignozzi, C. A.; Grätzel, M. J. Am. Chem. Soc. 2001, 123, 1613.

[4] Li, Q.; Wu, J.; Tang, Z.; Xiao, Y.; Huang, M.; Lin, J. Electrochim. Acta 2010, 55, 2777.

[5] Sakurai, S.; Jiang, H.; Takahashi, M.; Kobayashi, K. Electrochim. Acta 2009, 54, 5463.

[6] Siegers, C.; Oláh, B.; Würfel, U.; Hohl-Ebinger, J.; Hinsch, A.; Haag, R. Sol. Energy Mater. Sol. Cells. 2009, 93, 552.

[7] Hoshokawa, T.; Ikebe, T.; Kikuchi, R.; Eguchi, K. Electrochim. Acta 2006, 51, 5286.

[8] Kusama, H.; Orita, H.; Sugihara, H. Langmuir 2008, 24, 4411.

[9] Dijkgraaf, I.; Rijnders, A. Y.; Soede, A.; Dechesne, A. C.; Esse, G. W.; Brouwer, A. J.; Corstens, F. H. M.; Boerman, O. C.; Rijkers, D. T. S.; Liskamp, R. M. J. Org. Biomol. Chem. 2007, 5, 935 .

[10] Jarowski, P. D.; Wu, Y. L.; Schweizer, W. B.; Diederich, F. Org. Lett. 2008, 10, 3347.

[11] Liao, C.; Wang, Y.; Huang, C.; Sheu, H.; Lee, G.; Lai, C. K. Tetrahedron 2007, 63, 12437.

[12] Toa, Y.; Xu, Q.; Lu, J.; Yang, X. Dyes and Pigments 2010, 84, 153.

[13] Granadino-Roldán, J. M.; Garzón, A.; García, G.; Peña-Ruiz, T.; Fernández-Liencres, M. P.; Navarro, A.; Fernández -Gómez, M. J. Chem. Phys. 2009, 130, 234907.

[14] Bushmarinov, I. S.; Antipin, M. Y.; Akhmetova, V. R.; Nadyrgulova, G. R.; Lyssenko, K. A. J. Phys. Chem. A 2008, 112, 5017.

[15] El Azab, I.H.; Elkanzi, N. A. A. Design, Synthesis, and Antimicrobial Evaluation of New Annelated Pyrimido[2,1-c][1,2,4]triazolo[3,4-f][1,2,4]triazines. Molecules 2020, 25, 13391356.

[16] El Azab, I.H.; Elkanzi, N. A. A. An Efficient Synthetic Approach Towards Benzo[b]pyrano[2,3-e][1,4]diazepines and Their Cytotoxic Activity. Molecules 2020, 25, 20512065.

[17] El Azab, I.H.; Abu Ali, O.A.; El-Zahrani, A.H.; Gobouri, A.A.; Altalhi, T.A. Pyrazole-1carbothioamide as a Potent Precursor for Synthesis of Some New N-heterocycles of Potential Biological Activity. J. Heterocycl. Chem. 2019, 56, 18-31.

[18] El Azab, I.H.; Gobouri, A.A.; Altalhi, T.A. 4-Chlorothiazole-5-carbaldehydes as Potent Precursors for Synthesis of Some New Pendant N-heterocyces Endowed with Anti-Tumor Activity. J. Heterocycl. Chem. 2019, 56, 281-295. 
[19] El Azab, I.H.; Elkanzi, N.A.A.; Gobouri, A.A.; Altalhi, T.A. Convenient Synthesis of Novel Nitrogen Bridgehead Heterocycles Utilizing 3-Mercapto-6H-[1,2,4,5]oxatriazino[3,2-a] isoindol6-one as a New Synthon. J. Heterocycl. Chem. 2019, 56, 60-72.

[20] El Azab, I.H.; Abu Ali, O.A.; El-Zahrani, A.H.; Gobouri, A.A.; Altalhi, T.A. Pyrazole-1carbothioamide as a Potent Precursor for Synthesis of Some New N-heterocycles of Potential Biological Activity. J. Heterocycl. Chem. 2019, 56, 18-31.

[21] El Azab, I.H.; Khalifa, M.E.; Gobouri, A.A.; Altalhi, T.A. Synthesis, Characterization, and Pharmacological Evaluation of Some New Pteridine-Based Heterocycles as Antimicrobial Agents. J. Heterocycl. Chem. 2019, 56, 1352-1361.

[22] A. Al-Hossainy, M. Sh. Zoromba, O. El-Gammal, F.I. El-Dossoki, Density functional theory for investigation of optical and spectroscopic properties of zinc-quinonoid complexes as semiconductor materials, Structural Chemistry, 30 (2019) 1365-1380.

[23] P.L. Torraca, M. Bobinger, M. Servadio, P. Pavan, M. Becherer, P. Lugli, L. Larcher, On the frequency response of nanostructured thermoacoustic loudspeakers, Nanomaterials, 8 (2018) 833.

[24] T.T. Lin, X.Y. Liu, C. He, A DFT study on poly (lactic acid) polymorphs, Polymer, 51 (2010) 2779-2785.

[25] L.C. Shuller-Nickles, W.M. Bender, S.M. Walker, U. Becker, Quantum-mechanical methods for quantifying incorporation of contaminants in proximal minerals, Minerals, 4 (2014) 690715.

[26] P.M. Gill, B.G. Johnson, J.A. Pople, M.J. Frisch, The performance of the Becke-LeeYang-Parr (B-LYP) density functional theory with various basis sets, Chemical Physics Letters, 197 (1992) 499-505.

[27] S.M. Ibrahim, A.F. Al-Hossainy, Synthesis, structural characterization, DFT, kinetics and mechanism of oxidation of bromothymol blue: application to textile industrial wastewater treatment, Chemical Papers, DOI (2020) 1-13.

[28] A. Abd-Elmageed, S. Ibrahim, A. Bourezgui, A. Al-Hossainy, Synthesis, DFT studies, fabrication, and optical characterization of the [ZnCMC] TF polymer (organic/inorganic) as an optoelectronic device, New Journal of Chemistry, DOI (2020).

[29] O.A. Mostovaya, V.V. Gorbachuk, O.B. Bazanova, A.V. Gerasimov, V.G. Evtugyn, Y.N. Osin, V.D. Myakushev, I.K. Rizvanov, I.I. Stoikov, Thiacalixarene "knot" effect on protein binding by oligolactic acid particles, Materials Chemistry Frontiers, 3 (2019) 292-300.

[30] A.F. Al-Hossainy, R.M. Abdelaal, W.N. El Sayed, Novel synthesis, structure characterization, DFT and investigation of the optical properties of cyanine dye/zinc oxide [4-CHMQI/ZnO] C nanocomposite thin film, Journal of Molecular Structure, 1224 (2020) 128989.

[31] C.V. Reddy, I.N. Reddy, K.R. Reddy, S. Jaesool, K. Yoo, Template-free synthesis of tetragonal Co-doped $\mathrm{SiO} 2$ nanoparticles for applications in electrochemical energy storage and water treatment, Electrochimica Acta, 317 (2019) 416-426.

[32] M. Sh. Zoromba, A. Al-Hossainy, Doped poly (o-phenylenediamine-co-p-toluidine) fibers for polymer solar cells applications, Solar Energy, 195 (2020) 194-209. 
[33] M. Sh. Zoromba, M. Tashkandi, A. Alshehri, M. Abdel-Aziz, M. Bassyouni, S. Mahmoud, A.B. Slimane, A. Al-Hossainy, Polymer solar cell based on doped o-anthranilic acid and oaminophenol copolymer, Optical Materials, 104 (2020) 109947.

[34] H.K. Thabet, A. Al-Hossainy, M. Imran, Synthesis, characterization, and DFT modeling of novel organic compound thin films derived from 2-amino-4-(2-hydroxy-3-methoxyphenyl)-4Hthiazolo [3, 2-a][1, 3, 5] triazin-6 (7H)-one, Optical Materials, 105 (2020) 109915.

[35] I.T. Zedan, N.A. El-Ghamaz, E.M. El-Menyawy, Mater. Sci. Semicond. Process. 39 (2015) 408415.

[36] E. Corazza, S. Menchetti, C. Sabelli, The crystal structure of biringuccite, Na4 [B10O16 $(\mathrm{OH}) 2] \cdot 2 \mathrm{H} 2 \mathrm{O}$, American Mineralogist: Journal of Earth and Planetary Materials, 59 (1974) 10051015.

[37] J. Laugier, B. Bochu, LMGP-suite Suite of Programs for the Interpretation of X ray experiments, ENSP/Laboratoire des Materiaux et du Genie Physique, 2000. BP46 38042, Saint Martin d'Heres, France.

[38] D. Díaz-Guzmán, F. Legorreta-García, N.K. Pérez-González, M.I. Flores-Zamora, M. VargasRamírez, V.E. Reyes-Cruz, Breve crónica y aplicación de dos criterios de apoyo para la identificación de una clinoptilolita, Pädi Boletín Científico de Ciencias Básicas e Ingenierías del ICBI, 8 (2020) 33-40.

[39] A. Farouk Al-Hossainy, A. Ibrahim, The effects of annealing temperature on the structural properties and optical constants of novel DPEA-MR-Zn organic crystalline semiconductor nanostructure thin films, Optical Materials 73 (2017) 138-153.

[40] A.F. Al-Hossainy, A. Ibrahim, Structural, optical dispersion and dielectric properties of novel chromium nickel organic crystalline semiconductors, Materials Science in Semiconductor Processing, 38 (2015) 13-23.

[41] S. Takebayashi, T. Kunieda, N. Yoshinaga, K. Ushioda, S. Ogata, Comparison of the dislocation density in martensitic steels evaluated by some X-ray diffraction methods, ISIJ international, 50 (2010) 875-882.

[42] H.K. Thabet, A. Al-Hossainy, M. Imran, Synthesis, characterization, and DFT modeling of novel organic compound thin films derived from 2-amino-4-(2-hydroxy-3-methoxyphenyl)-4Hthiazolo [3, 2-a][1, 3, 5] triazin-6 (7H)-one, Optical Materials, 105 (2020) 109915.

[43] D.T. Reis, I.H.S. Ribeiro, D.H. Pereira, DFT study of the application of polymers cellulose and cellulose acetate for adsorption of metal ions $(\mathrm{Cd} 2+, \mathrm{Cu} 2+$ and $\mathrm{Cr} 3+)$ potentially toxic, Polymer Bulletin, 77 (2020) 3443-3456.

[44] P. Mori-Sánchez, Q. Wu, W. Yang, Accurate polymer polarizabilities with exact exchange density-functional theory, The Journal of chemical physics, 119 (2003) 11001-11004.

[45] P. Demir, F. Akman, Molecular structure, spectroscopic characterization, HOMO and LUMO analysis of PU and PCL grafted onto PEMA-co-PHEMA with DFT quantum chemical calculations, Journal of Molecular Structure, 1134 (2017) 404-415.

[46] T. Taha, N. Hendawy, S. El-Rabaie, A. Esmat, M. El-Mansy, Effect of NiO NPs doping on the structure and optical properties of PVC polymer films, Polymer Bulletin, 76 (2019) 4769-4784.

[47] Z. Asadi, M. D. Esrafili, E. Vessally, M. Asnaashariisfahani, S. Yahyaei, A. Khani, A structural study of fentanyl by DFT calculations, NMR and IR spectroscopy, Journal of Molecular Structure 1128 (2017) $552-562$. 
[48] H. Howari , J. Nat. Sci. Math. 5 (2012)139-154.

[49] A. Ashery, A.A.M. Farag, M.A. Shenashen, Synth. Met. 162 (2012) 1357- 1363.

[50] A.A.M. Farag, A.Ashery, M.A.Shenashen, Physica B 407 (2012) 2404-2411.

[51] A. Gavrilenko, S.M. Black, A. Sykes, C.E. Bonner, V.I. Gavrilenko, Computations of Ground State and Excitation Energies of Poly (3-methoxy-thiophene) and Poly (thienylene vinylene) from First Principles, International Conference on Computational Science, Springer, 2008, pp. 396404.

[52] S.M. Ibrahim, A. Bourezgui, A. Abd-Elmageed, I. Kacem, A.F. Al-Hossainy, Structural and optical characterization of novel [ZnKCMC] TF for optoelectronic device applications, Journal of Materials Science: Materials in Electronics, 31 (2020) 8690-8704.

[53] M. Dutta, S. Mridha, D. Basak, Appl. Surf. Sci. 254 (9) (2008) 2743-2747.

[54] E.F. Keskenler, G. Turgut, S. Dogan, Superlattice. Microst. 52 (1) (2012) 107-115.

[55] A.F. Al-Hossainy, Bull. Mater. Sci. 39 (1) (2016) 209-222.

[56] S. Shukla, S. Kumar, Pramana 78 (2) (2012) 309-318.

[57] W.E. Mahmoud, A.A. Al-Ghamdi, S. Al-Heniti, S. Al-Ameer, J. Alloys Compd. 491 (1) (2010) $742-746$.

[58] R. Wen, L. Wang, X. Wang, G.-H. Yue, Y. Chen, D.-L. Peng, J. Alloys Compd. 508 (2) (2010) 370-374.

[59] Ahmed F. Al-Hossainy, Reda M. Abdelaal, Wesam N. El Sayed, Journal of Molecular Structure $1224(2021) 128989$

[60] S. Ilican, Y. Caglar, M. Caglar, F. Yakuphanoglu, Physica E 35 (2006) 131-133.

[61] K. Tanaka, Thin Solid Films 66 (1980) 271-279.

[62] H. M. Zeyada, M.M. EL-Nahass, I.S. Elashmawi, A.A. Habashi, J. Non-Cryst. Solids 358 (2012) 625-636.

[63] S.H. Alotaibi, A.S. Radwan, Y.K. Abdel-Monem, M.M. Makhlouf, Synthesis, thermal behavior, and optical characterizations of thin films of a novel thiazole azo dye and its copper complexes, Spectrochim. Acta A Mol. Biomol. Spectrosc. 205 (2018) 364-375

[64] J. Singh, Optical Properties of Condensed Matter and Applications, John Wiley \& Sons, 2006.

[65] P. Capper, S. Kasap, Springer Handbook of Electronic and Photonic Materials, Springer, 2006.

[66] M.A.Mahdi,S.K.J.A-Ani,Int.J.Nano-electron 5(2012)11-24.

[67] A.A.M. Farag, M. Abdel Rafea, N. Roushdy, O. El-Shazly, E.F. El-Wahidy, Journal of Alloys and Compounds, (2014), doi: http://dx.doi.org/10.1016/j.jallcom.2014.09.091.

[68] S.H. Wemple, Phys. Rev. B 7 (1973) 3767-3777.

[69] M. Caglar, M. Zor, S. Ilican, Y. Caglar, Czech. J. Phys. 56(2006) 277-281.

[70] M.A.Mahdi,S.K.J.A-Ani,Int.J.Nano-electron 5(2012)11-24.

[71] M.Okutan, S.Eren San, O.Koysal, F.Yakuphanoglu, Physica B 362 (2005)180-186.

[72] J. Singh, Optical Properties of Condensed Matter and Applications, John Wiley \& Sons, 2006.

[73] H. Huang, L. Zhang, Y. Wang, X.D. Han, Y. Wu, Z. Zhang, F. Gan, J. Alloys Compd. 509 (2011) 5050-5054.

[74] M.C. Gupta, Handbook of Photonics,CRC Press, Boca Raton, FL, 1997.

[75] F. Yakuphanoglu, M. Sekerci, O.F. Ozturk, Opt. Commun. 239 (2004) 275-280. 
Figures

(a)

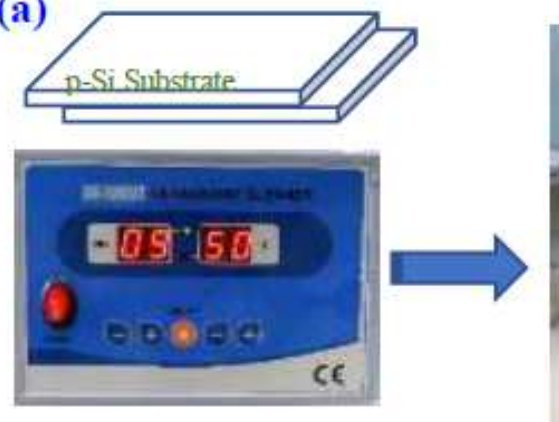

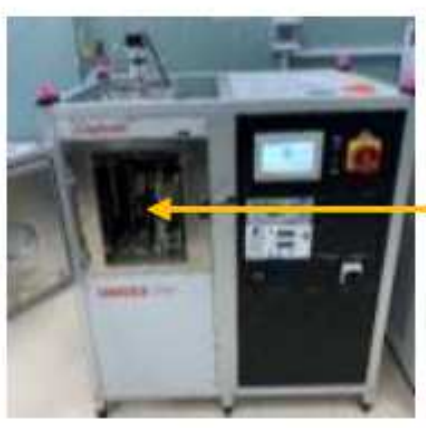
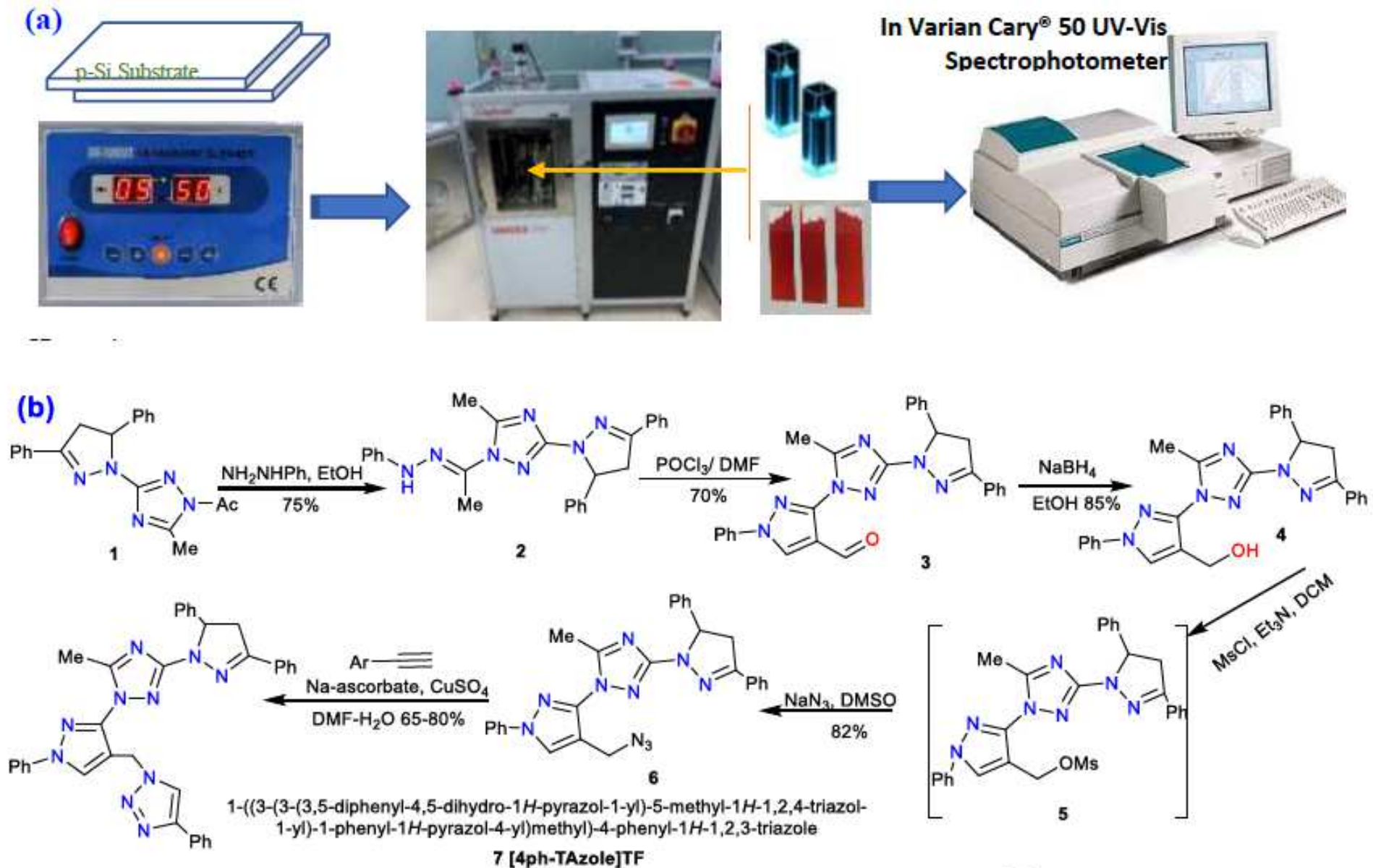

$\cos ^{2}$

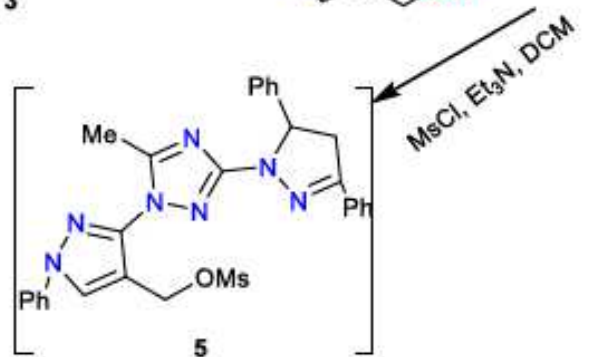

7 [4ph-TAzole]TF

Figure 1

(a-b) Fabrication and chemical structure of [4ph-TAzole]TF thin film. 

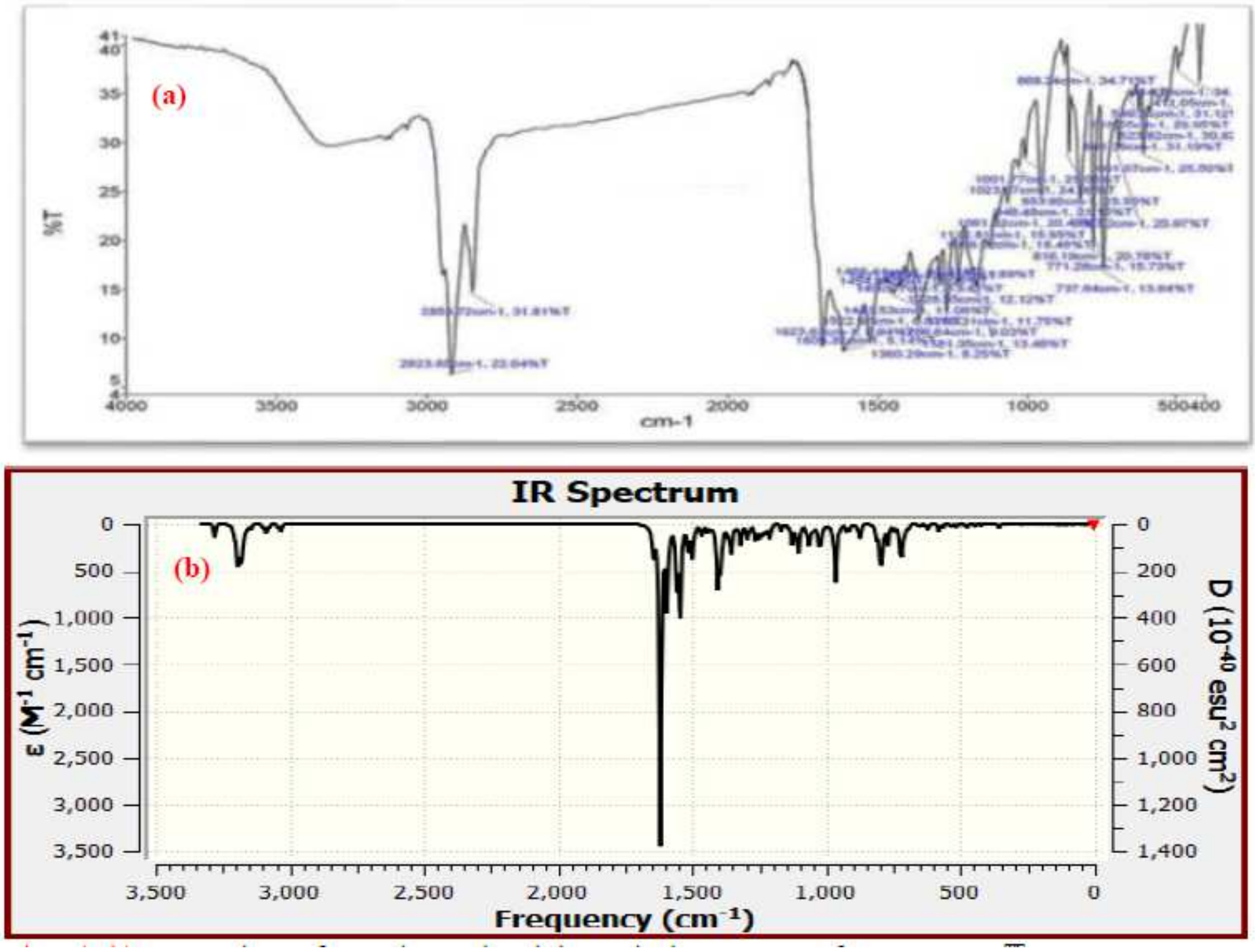

Figure 2

(a-b) Comparison of experimental and theoretical IR spectra of [4ph-TAzole]TF and [4ph-TAzole] isolated molecule in gaseous state, respectively. 

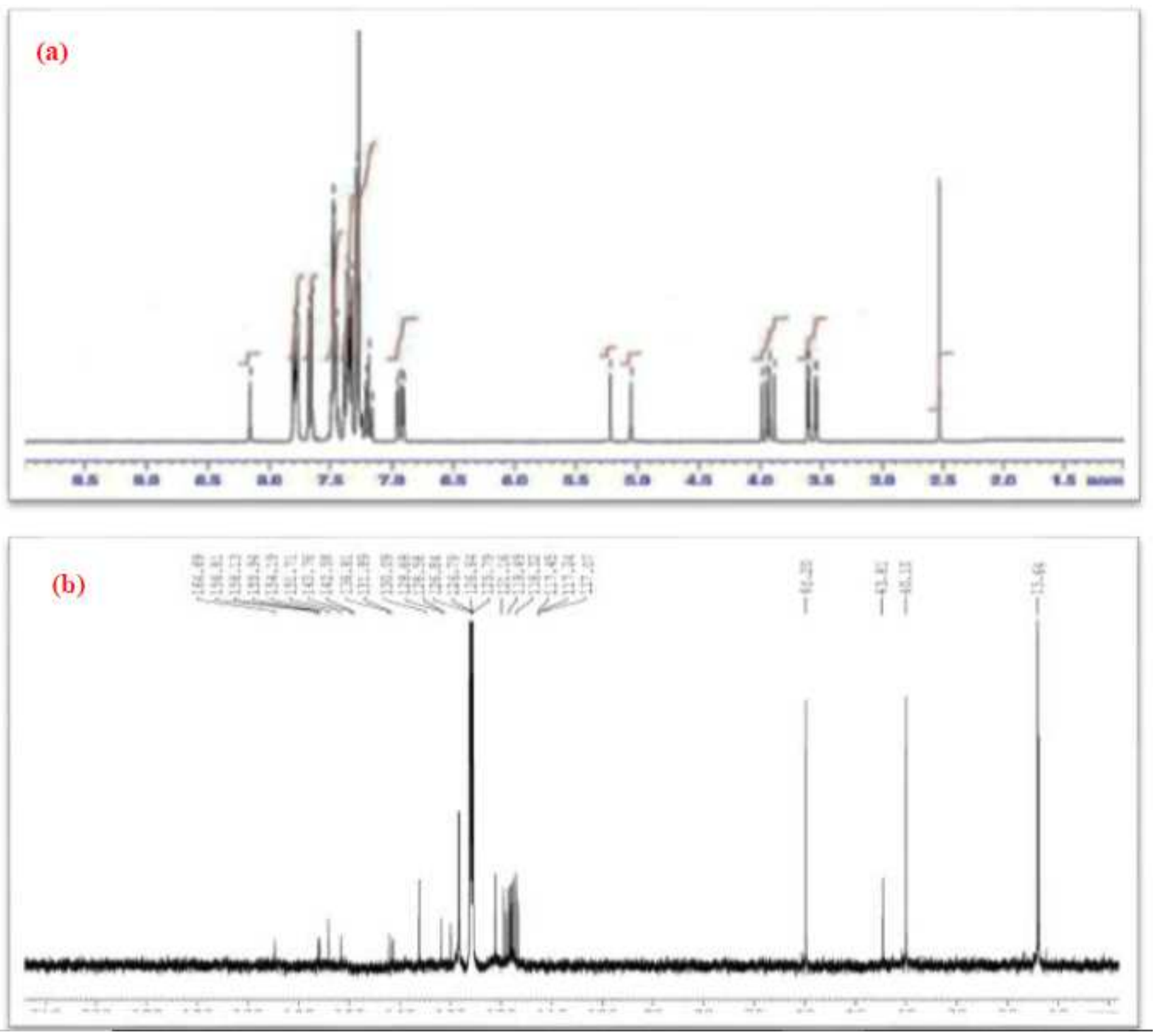

Figure 3

(a-b) Comparison of experimental and theoretical 1HNMR of [4ph-TAzole] isolated molecule in gaseous state. 


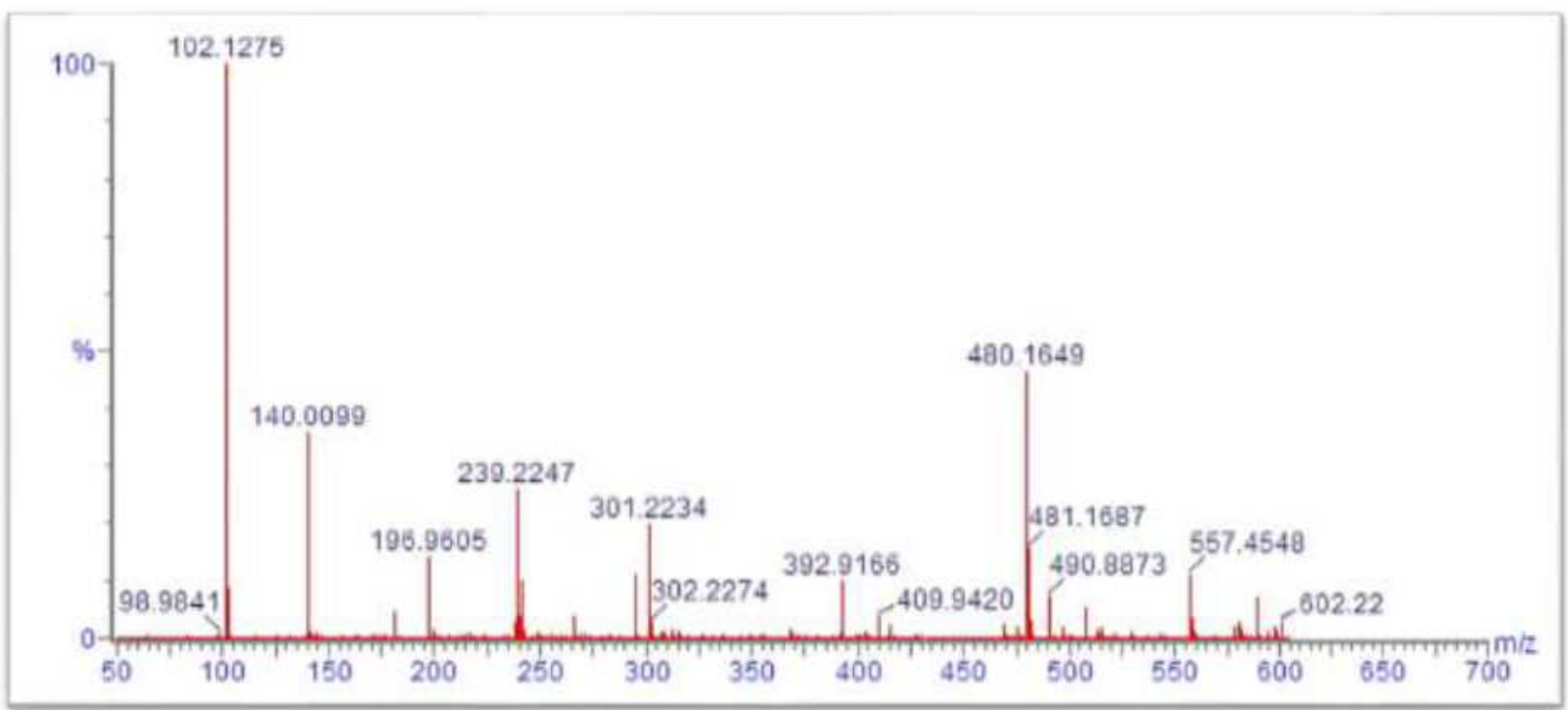

Figure 4

The experimental data mass spectrum of [4ph-TAzole].

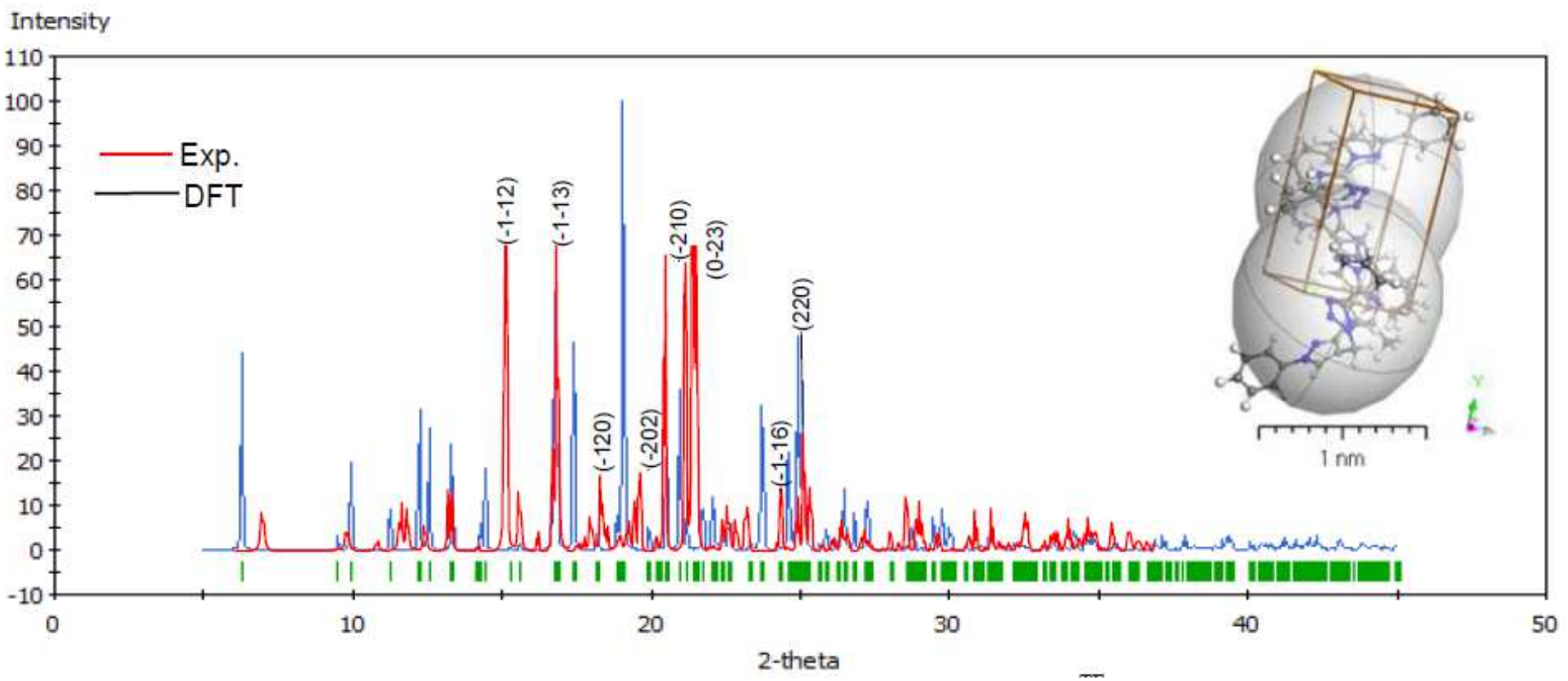

Figure 5

Combined experimental and simulated XRD patterns for [4ph-TAzole]TF thin film 

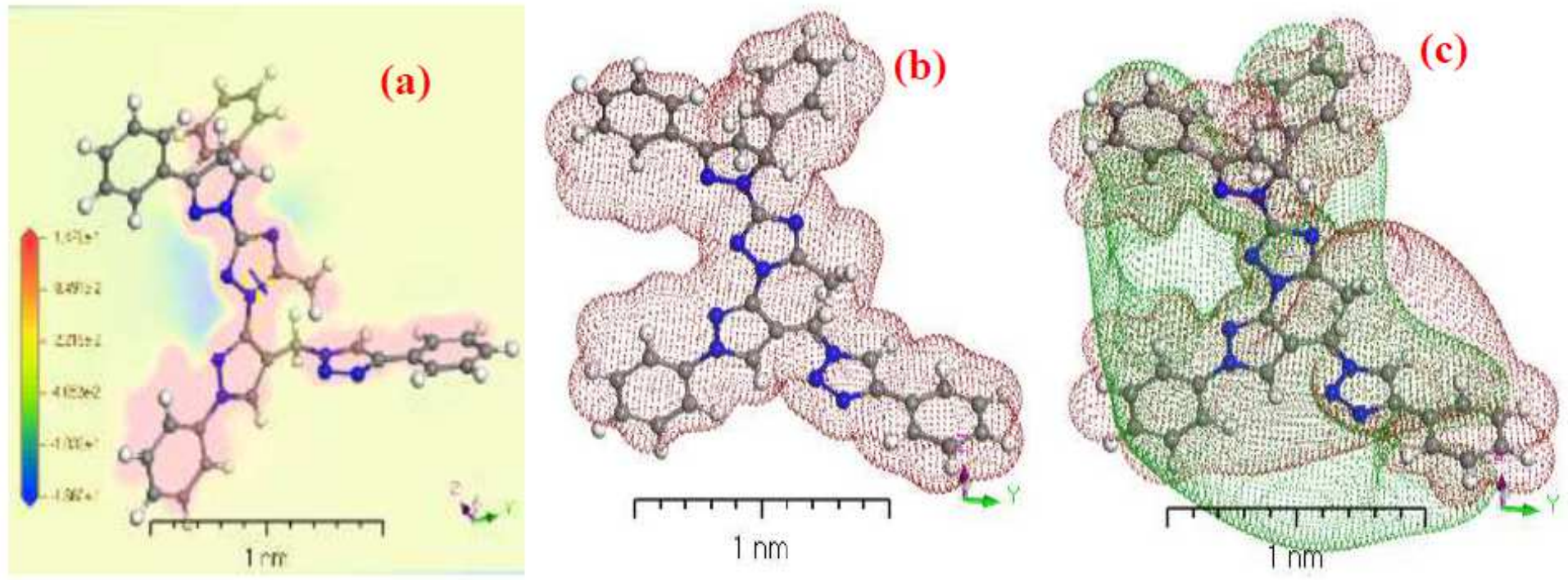

Figure 6

a) MEP of [4ph-TAzole] gas phase, b) Electron density of [4ph-TAzole] gas phase and c) Potential of [4phTAzole] gas phase utilizing Gaussian software and DMOI3/DFT programs 

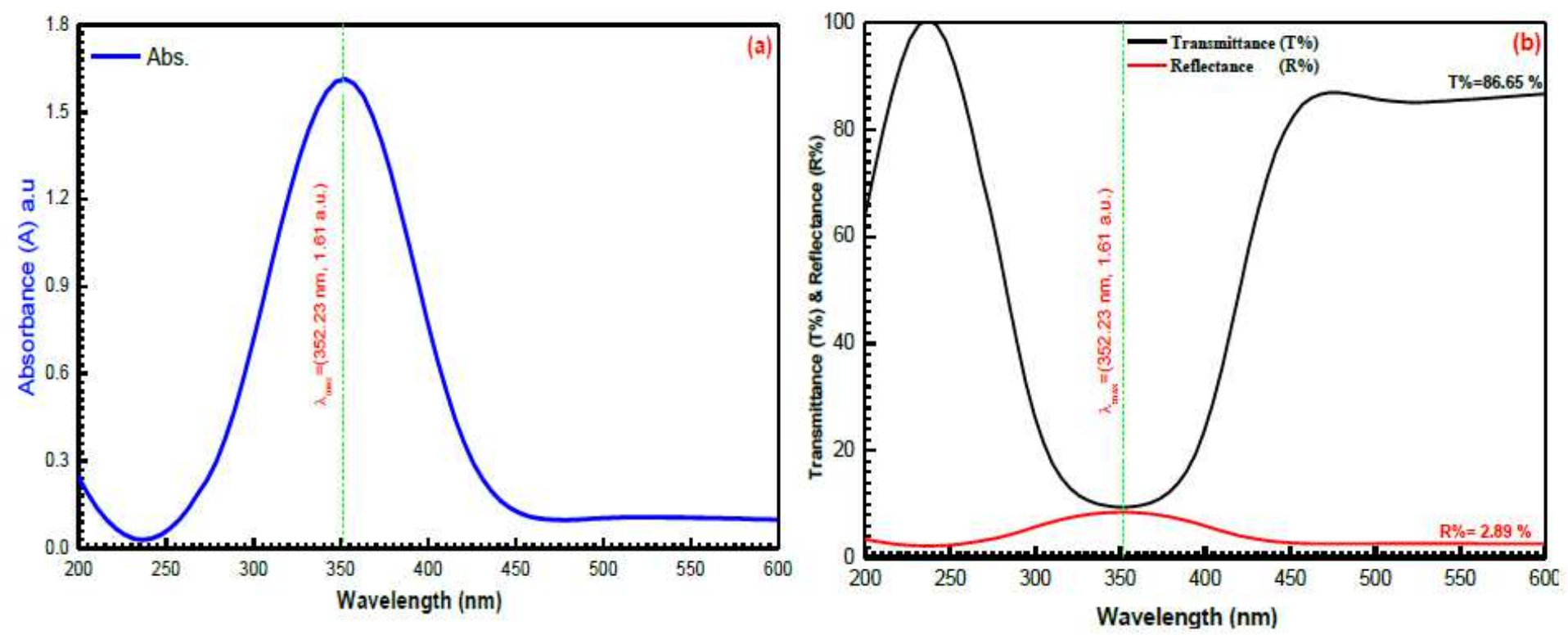

Absorption (cm-1)

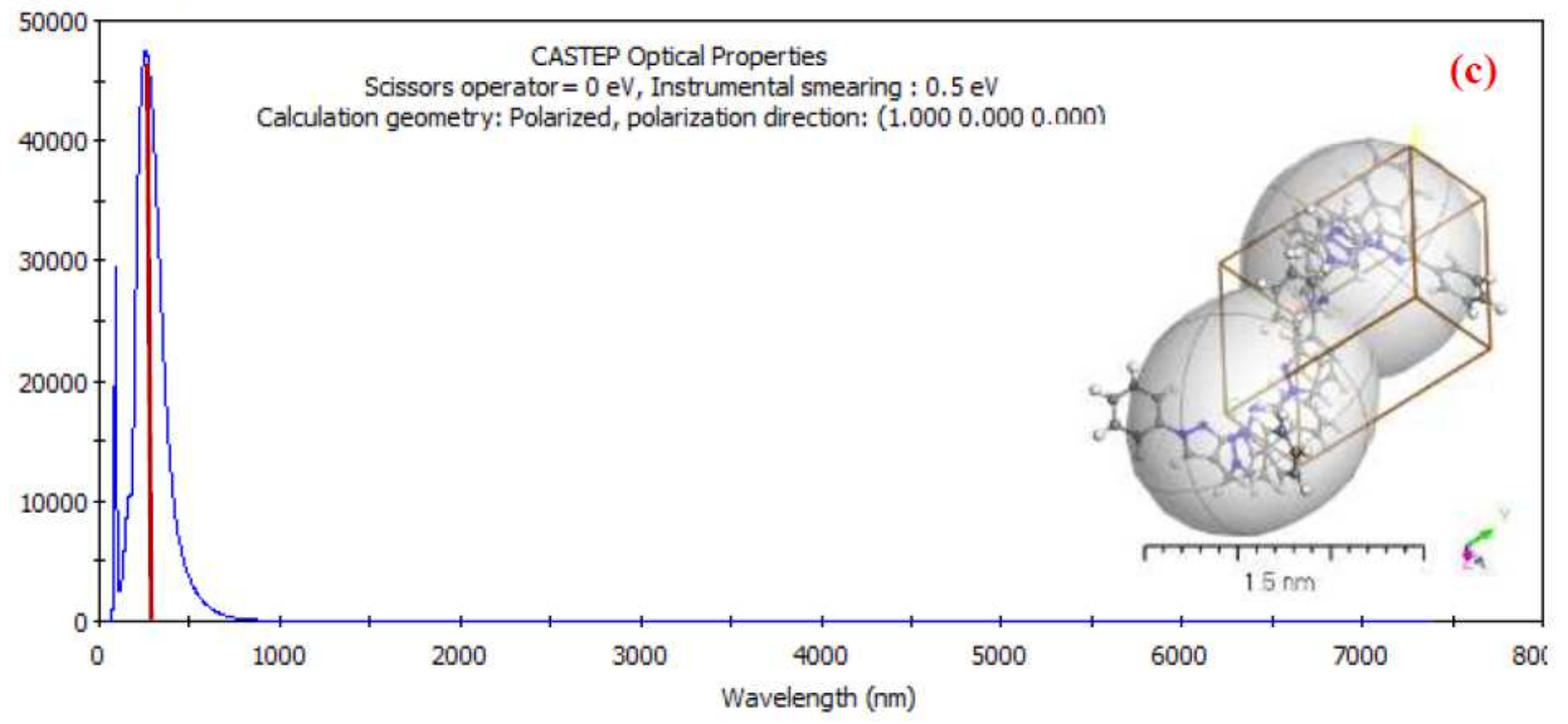

Figure 7

(a-b) Experimental absorbance (A); b) Experimental transmittance (T\%) and Reflectance (R\%) for the [4phTAzole]TF. c) Simulated absorption for the thin film as-gas phase using CATSTEP/DFT. 


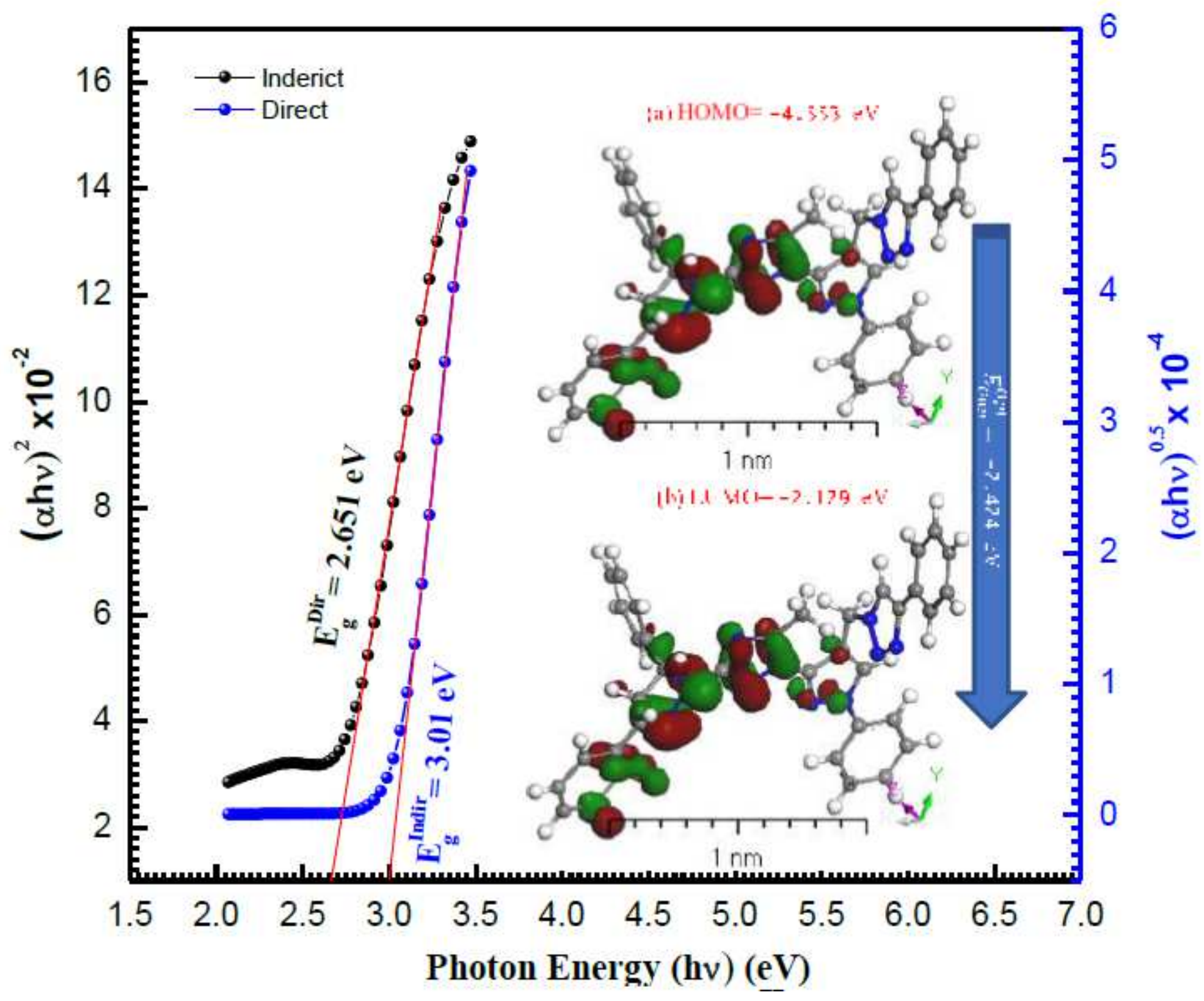

Figure 8

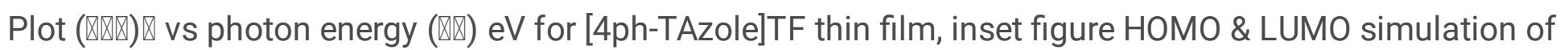
[4ph-TAzole] by using DMol3 method in DFT. 


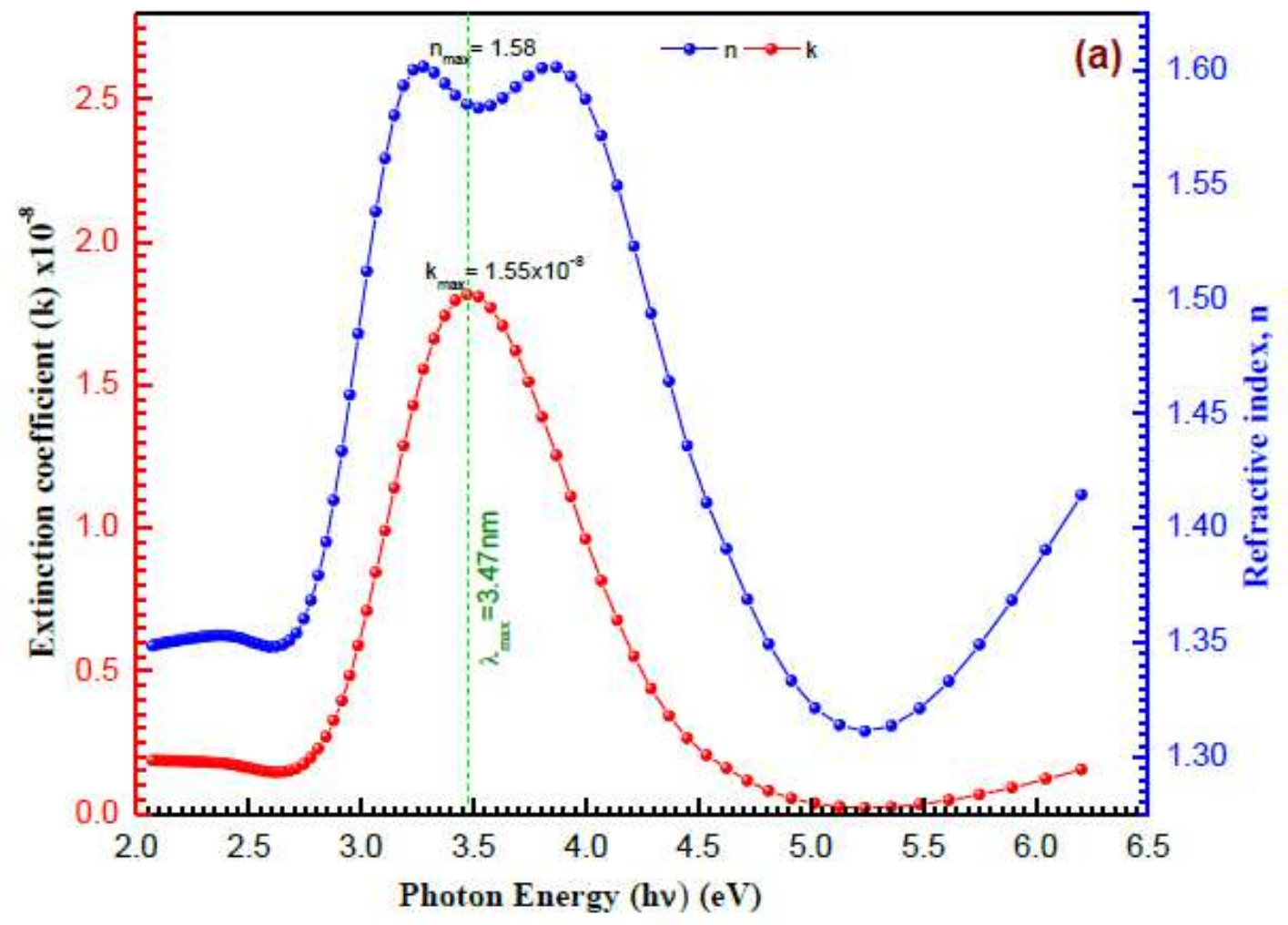

Refractive Index

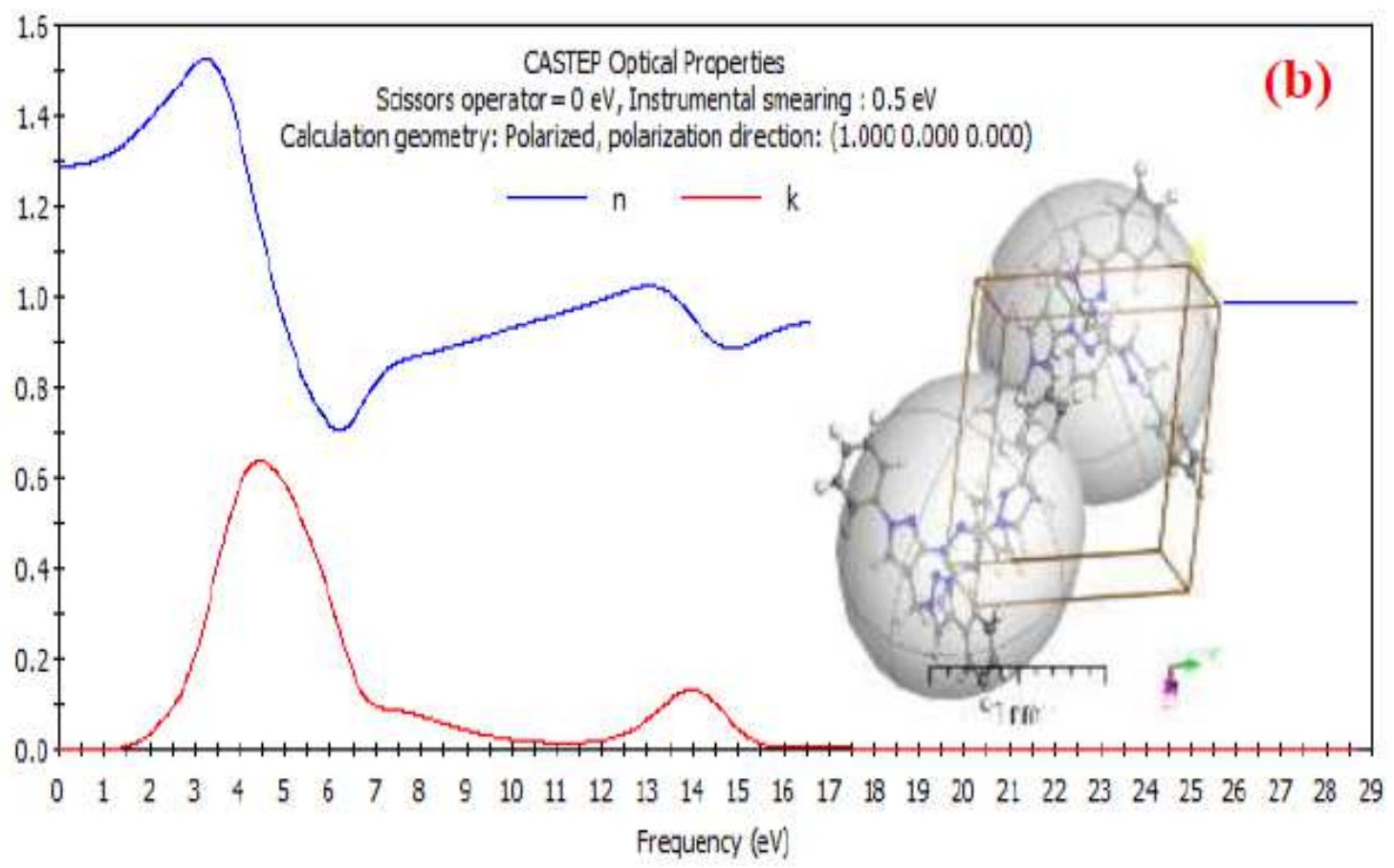

Figure 9

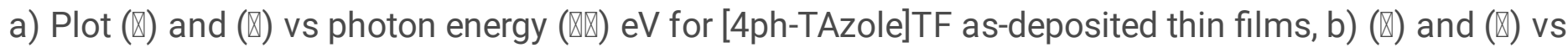
photon energy (怄) eV simulation of [4ph-TAzole]TF using CASTEP/DFT-TDDFT. 

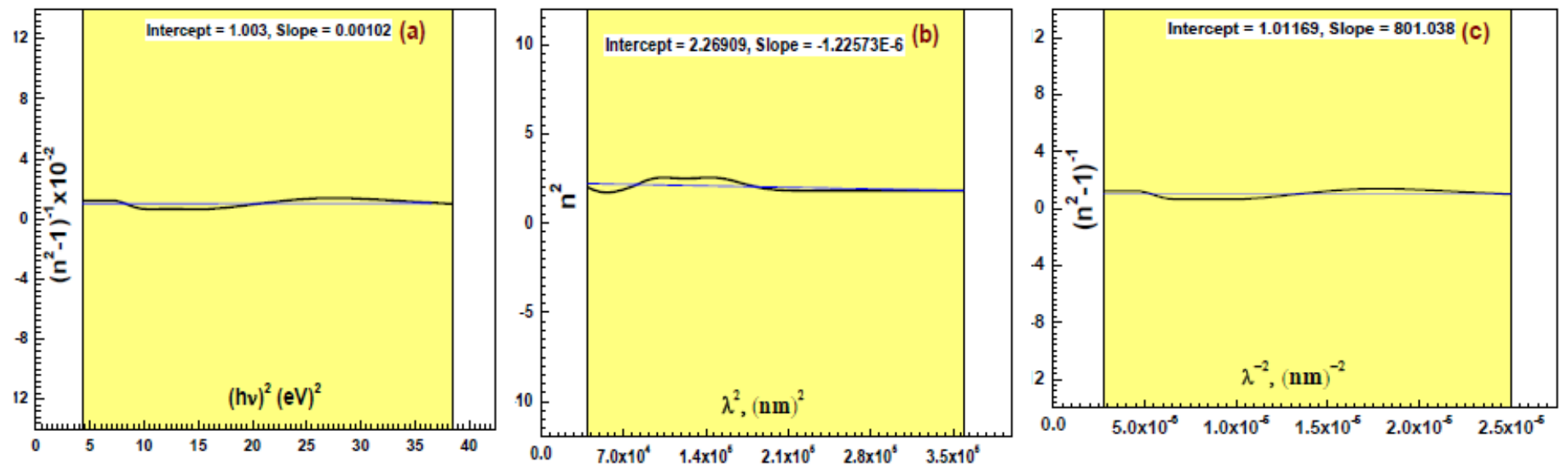

Figure 10

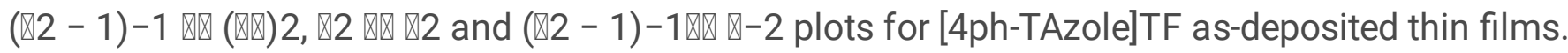




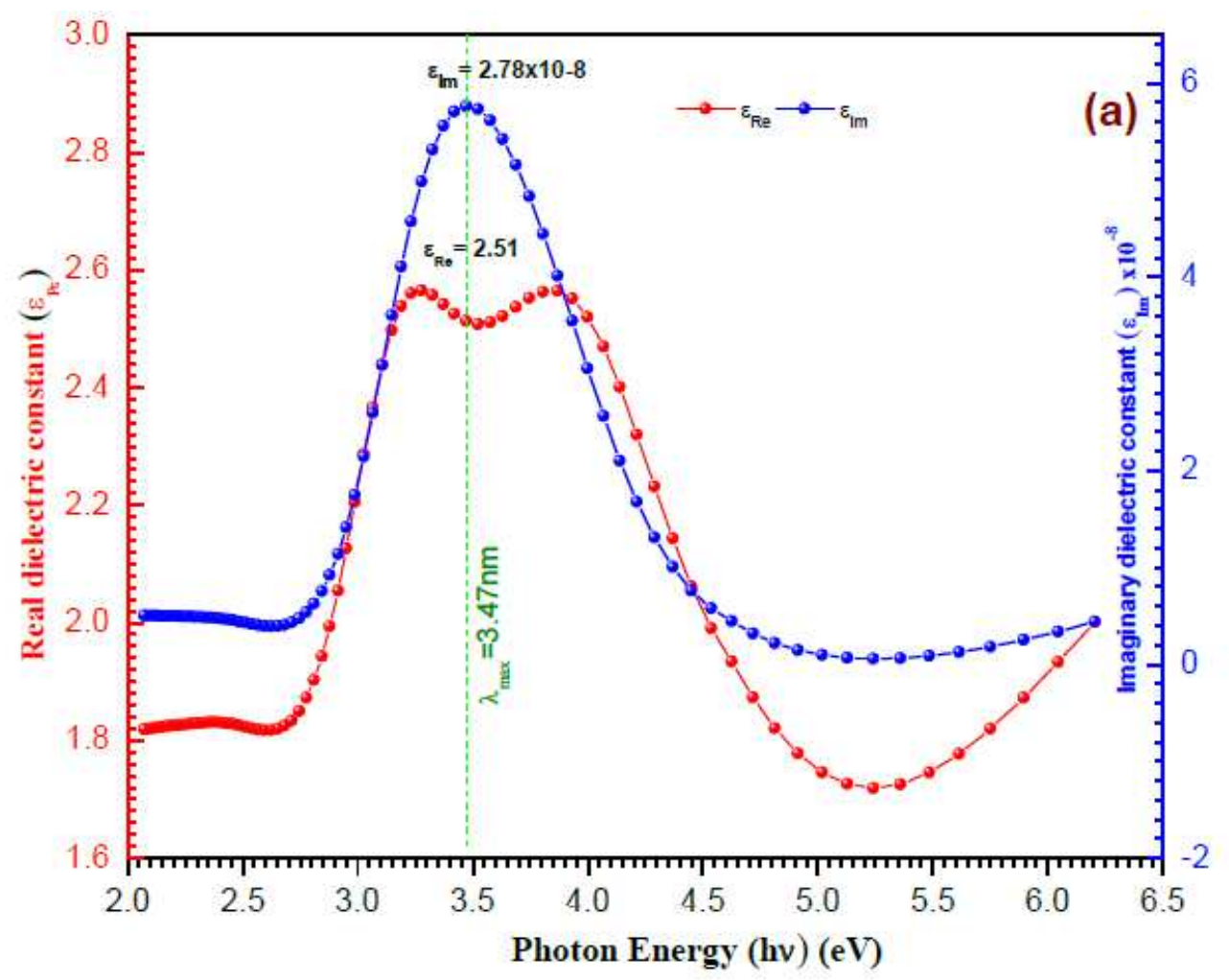

Dielectric Function

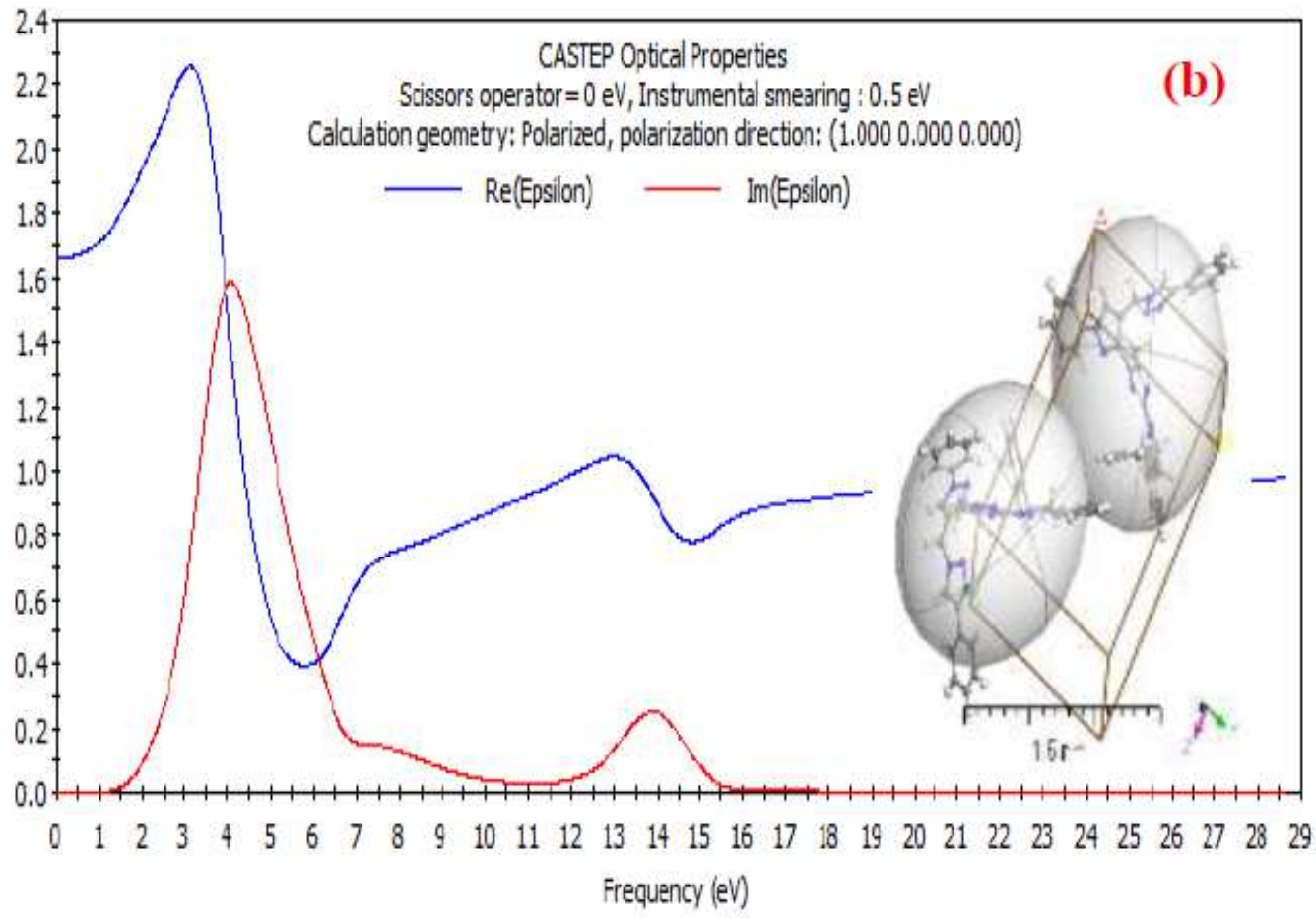

Figure 11

a) ( $\varepsilon \mathrm{Re})$ and ( $(\varepsilon \mathrm{Im})$ vs (hv) eV for [4ph-TAzole]TF thin film. b) Simulation dielectric function for [4phTAzole] by using CASTEP method. 


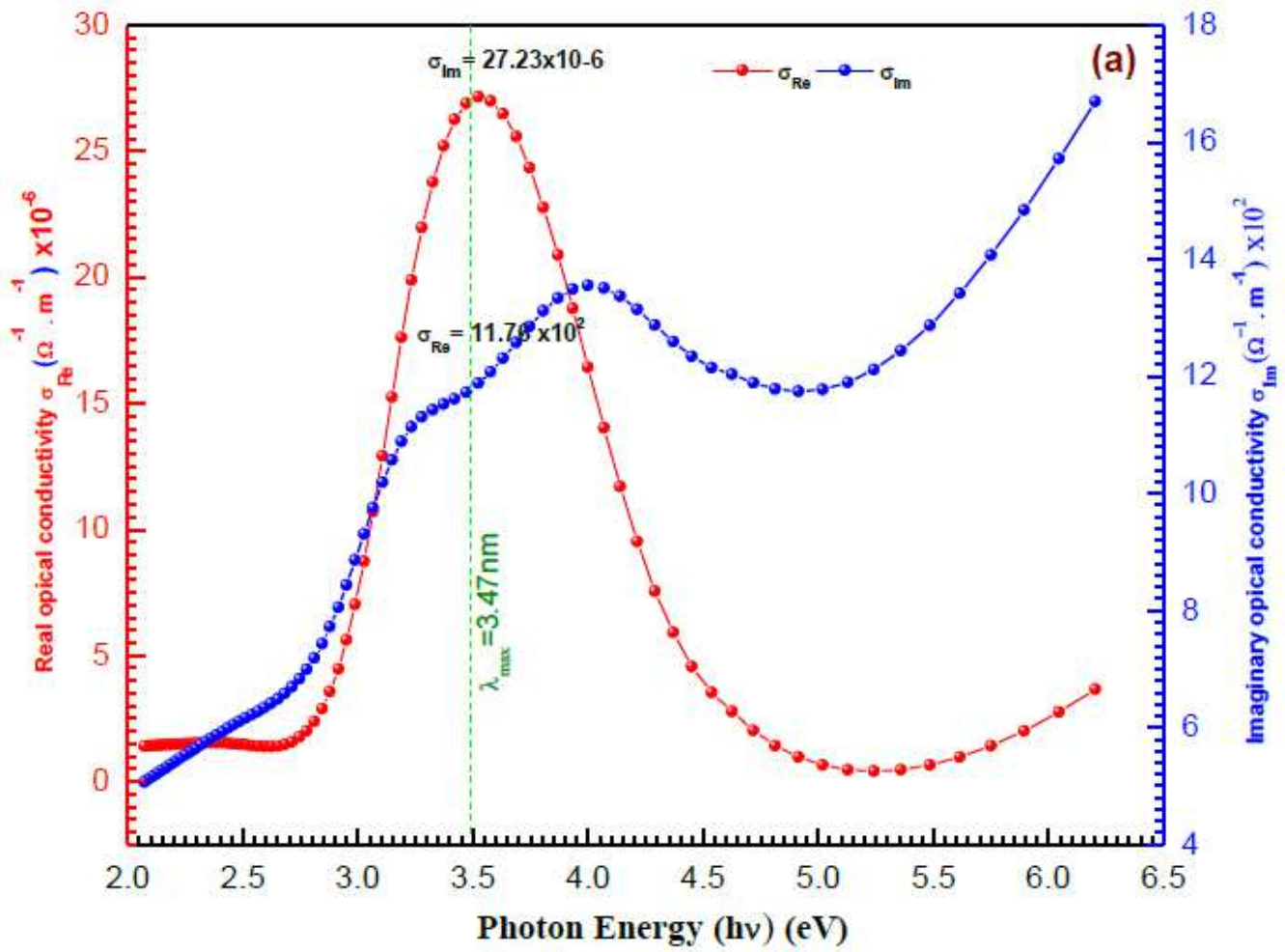

Conductivity (1//s)

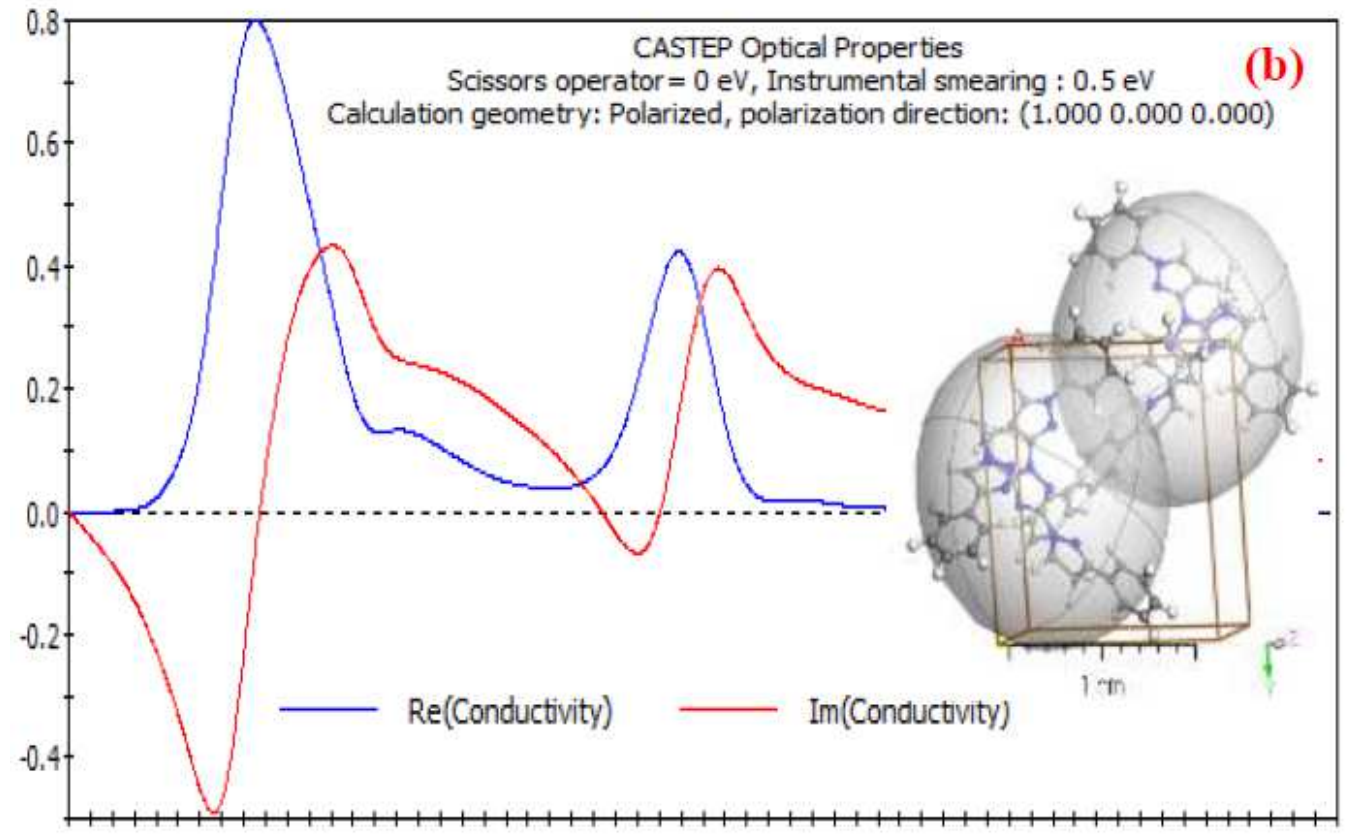

$\begin{array}{llllllllllllllllllllllllllllll}0 & 1 & 2 & 3 & 4 & 5 & 6 & 7 & 8 & 9 & 10 & 11 & 12 & 13 & 14 & 15 & 16 & 17 & 18 & 19 & 20 & 21 & 22 & 23 & 24 & 25 & 26 & 27 & 28 & 29\end{array}$ Frequency (el)

Figure 12

a) ( $\sigma \mathrm{Re})$ and ( $\sigma \mathrm{lm})$ vs (hv) eV for [4ph-TAzole]TF thin film. b) Simulation conductivity function for [4phTAzole] by using CASTEP method. 